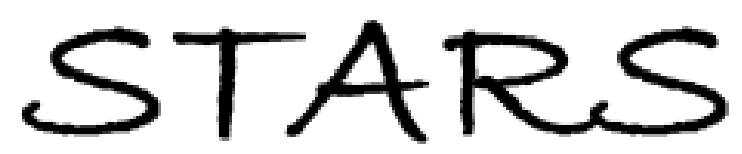

University of Central Florida

STARS

Retrospective Theses and Dissertations

1988

\title{
A Piezoelectric Actuated Scanning Mirror System Utilizing a Type One Control Loop
}

David Gibbs

University of Central Florida

Part of the Systems and Communications Commons

Find similar works at: https://stars.library.ucf.edu/rtd

University of Central Florida Libraries http://library.ucf.edu

This Masters Thesis (Open Access) is brought to you for free and open access by STARS. It has been accepted for inclusion in Retrospective Theses and Dissertations by an authorized administrator of STARS. For more information, please contact STARS@ucf.edu.

\section{STARS Citation}

Gibbs, David, "A Piezoelectric Actuated Scanning Mirror System Utilizing a Type One Control Loop" (1988). Retrospective Theses and Dissertations. 4282.

https://stars.library.ucf.edu/rtd/4282

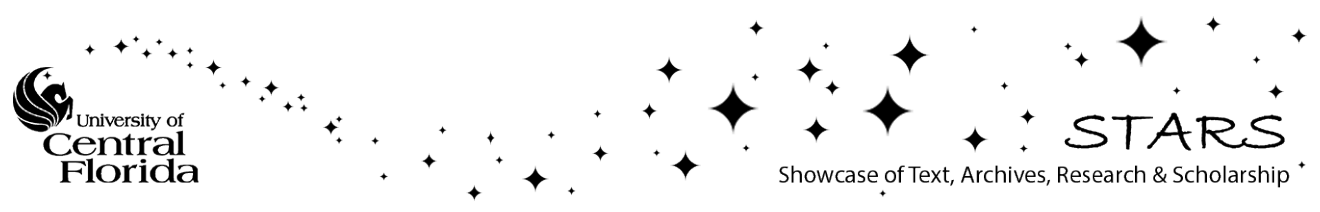


A PIEZOELECTRIC ACTUATED SCANNING MIRROR SYSTEM UTILIZING A TYPE ONE CONTROL LOOP

BY

DAVID MICHAEL GIBBS

B.S., University of New Hampshire, 1984

\section{THESIS}

Submitted in partial fulfillment of the requirements for the degree of Master of Science in Engineering in the Graduate Studies Program of the College of Engineering University of Central Florida orlando, Florida 


\section{ABSTRACT}

The purpose of this thesis is to design and build an improved control loop for a piezoelectric actuated scanning mirror system. A control system has been built having zero steady state position error and an $8 \varnothing$ Hertz bandwidth. This was achieved by placing the piezoelectric actuator in the feedback path of an operational amplifier and placing series cascaded notch filters and lead compensators in the forward path of the control loop. A prototype system, including compensation and feedback, is developed. Its performance compares favorably with that of the system model. It is capable of plus and minus 1.7 degrees of angular deflection. 
TABLE OF CONTENTS

LIST OF FIGURES....................... iv LIST of SYMBOLS........................ vi Chapter

1 INTRODUCTION...................... 1

2 PIEZOELECTRIC ACTUATORS................ 4

3 MODELING AND ANALYSIS................ 8

4 INITIAL DESIGN CONSIDERATIONS........... 28

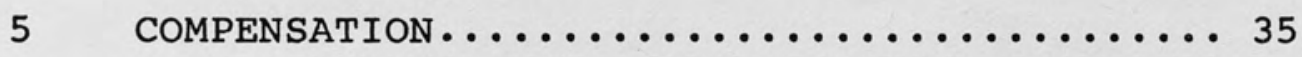

6 COMPENSATED SYSTEM ANALYSIS AND DESIGN..... 46

7 POSITION SENSOR.................. 58

$8 \quad$ RESULTS............................ 62

9 CONCLUSIONS AND EXTENSIONS............. 72

REFERENCES............................. 75 


\section{LIST OF FIGURES}

1. Bimorph Piezoelectric Actuator................ 7

2. Bimorph Actuated Scanning Mirror System......... 7

3. Actuator Lower Order Model..................

4. Actuator Input Impedance Photograph............ $1 \varnothing$

5. Actuator Input Impedance Graph.............

6. Open Loop Lower Order Model in Feedback Path...... 14

7. Closed Loop Lower Order Model in Feedback Path..... 16

8. Model With Electromechanical Scale Factor......... 18

9. Model With Scale Factor in Feedback Path......... 18

1Ø. Closed Loop Low Order Plant Model.............

11. High Order Input Impedance Photograph..........

12. Actuator Higher Order Model................. 23

13. Open Loop Higher Order Model in Feedback Path..... 23

14. Closed Loop High Order Plant Model............. 26

15. Root Locus of Uncompensated Plant............. 36

16. Biquadratic Notch Filter.................. 36

17. Lead Compensator....................... $4 \varnothing$

18. Root Locus of Lower Order Compensated Plant.......4ø

19. Root Locus of Higher Order Compensated Plant......44

2ø. Closed Loop System Model.................. 47

21. Closed Loop Pole Locations of Compensated Plant.... 52

22. Closed Loop system Circuit.................. 54

23. Uncompensated Plant Open Loop Response.......... 55 
24. Compensated Plant Open Loop Response.......... 56

25. Compensated Plant Closed Loop Response......... 57

26. Position Sensor Schematic...............6 6

27. Lower Order Lead Response................6 64

28. Higher Order Lead Response............... 65

29. Lower Order Lead Photographed Response.........66 66

30. Higher Order Lead Photographed Response.........66 66

31. Lower Order Biquad Response.............. 67

32. Higher Order Biquad Response..............6 68

33. Lower Order Biquad Photographed Response........ 69

34. Higher Order Biquad Photographed Response........ 69

35. Actual System Closed Loop Response........... 7ø

36. Photographed Step Response................ 71 


\section{LIST OF SYMBOLS}

\begin{tabular}{|c|c|}
\hline $\mathrm{A}_{\mathrm{N}}$ & Non-inverting Gain \\
\hline $\mathrm{A}_{\mathrm{L}}$ & Lead Compensator DC Gain \\
\hline BW & Difference of Two Bandpass Cutoff Frequencies \\
\hline C & Electrical Capacitance \\
\hline $\mathrm{C}_{\mathbf{i}}$ & i'th Electrical Capacitor Value \\
\hline$c_{m}$ & Mechanical Capacitance \\
\hline $\mathrm{C}_{\mathrm{H}}$ & Higher Order Mechanical Capacitance \\
\hline $\mathrm{C}_{\mathrm{e}}$ & Actuator Electrical Capacitance - \\
\hline $\mathrm{C}_{\mathrm{T}}$ & Sum of Electrical and Mechanical Capacitance \\
\hline $\mathrm{dVo}_{\mathrm{O}} / \mathrm{dt}(\max )$ & Maximum Rate of Change of opamp Output Voltage \\
\hline $\mathrm{E}_{1}$ & Steady State Actuator Model Output Error \\
\hline $\mathrm{E}_{\boldsymbol{\theta}}$ & Steady State Actuator Output Error \\
\hline$f_{1}^{3 d B}$ & Lower $3 \mathrm{~dB}$ Cutoff Frequency \\
\hline$f_{u}^{3 d B}$ & Upper 3aB Cutoff Frequency \\
\hline $\mathrm{H}_{\mathrm{OL}}(\mathrm{s})$ & $\begin{array}{l}\text { Lower Order Actuator Open Position } \\
\text { Transfer Function }\end{array}$ \\
\hline $\operatorname{Io}_{\mathrm{O}}(\max )$ & Maximum Opamp Output Current \\
\hline $\mathrm{K}_{1}$ & Free Integrator Forward Path Gain \\
\hline $\mathrm{K}_{r}$ & Feedback Gain Resistor Ratio \\
\hline $\mathrm{K}_{0}$ & Actuator Electromechanical Scale Factor \\
\hline $\mathrm{K}_{\mathrm{p}}$ & Position Sensor Scale Factor \\
\hline $\mathrm{K}_{\mathrm{DC}}$ & Overall DC Gain \\
\hline & \\
\hline
\end{tabular}


$K^{\prime}$

$\mathrm{K}_{\mathrm{v}}$

$L_{m}$

$\mathrm{L}_{\mathrm{H}}$

$\mathrm{M}_{1}$

$Q_{\mathbf{s}}$

$Q_{\mathrm{d}}$

$\mathrm{Q}_{\mathrm{p}}$

$\mathrm{Q}_{\mathrm{H}}$

R

$\mathrm{R}_{\mathbf{i}}$

$R_{m}$

$\mathrm{R}_{\mathrm{H}}$

$R_{\text {in }}$

$R_{f}$

$R_{r}$

s

$\mathbf{s}_{i}$

$t$

$\mathrm{Ta}_{\mathrm{L}}(\mathrm{s})$

$\mathrm{Ta}_{\mathrm{H}}(\mathrm{s})$

$\mathrm{T}_{\mathrm{L}}(\mathrm{s})$

$\mathrm{T}_{\mathrm{LH}}(\mathrm{s})$

$\mathrm{T}_{\mathrm{N}}(\mathrm{s})$
Overall Adjustable Loop Gain

Steady State Ramp Error Coefficient

Mechanical Inductance

Higher Order Mechanical Inductance

Slope of Reference Input Voltage

Series Resonance Quality Factor

Biquadratic Notch Filter Quality Factor

Parallel Resonance Quality Factor

Higher Order Mechanical Resonance Quality Factor

Electrical Resistance

i'th Electrical Resistor Value

Mechanical Resistance

Higher Order Mechanical Resistance

Plant Input Resistance

Feedback Resistance

Reference Input Resistance

Laplace Transform operator

$i$ 'th pole/zero frequency value

Time

Lower Order Actuator Model Transfer Function Higher Order Actuator Model Transfer Function Lead Compensator Transfer Function

Higher order Lead Compensator Transfer Function

Biquadratic Notch Filter Transfer Function 


$\begin{array}{ll}\mathrm{T}_{\mathrm{NH}}(\mathrm{s}) & \begin{array}{l}\text { Higher Order Biquadratic Notch Filter Transfer } \\ \text { Function }\end{array} \\ \mathrm{T}_{\mathrm{OL}}(\mathrm{s}) & \begin{array}{l}\text { Lower Order Actuator Model Open Position Loop } \\ \text { Transfer Function }\end{array} \\ \mathrm{T}_{\mathrm{OH}}(\mathrm{s}) & \begin{array}{l}\text { Higher Order Actuator Model Open Position } \\ \text { Loop Transfer Function }\end{array} \\ \mathrm{T}_{\mathrm{OHC}}(\mathrm{s}) & \begin{array}{l}\text { Higher Order Model Compensated Open } \\ \text { Position Loop Transfer Function }\end{array} \\ \mathrm{T}_{\mathrm{OF}}(\mathrm{s}) & \begin{array}{l}\text { Higher Order Model's Fully Compensated Open } \\ \mathrm{Vo}_{\mathrm{A}}\end{array} \\ \mathrm{Vi}_{\mathrm{A}} & \text { Output Voltage of Actuator Model } \\ \mathrm{V}_{\mathrm{r}} & \text { Input Voltage to Actuator Model } \\ \mathrm{V}_{\mathrm{p}} & \text { Reference Input Voltage } \\ \mathrm{V}_{\mathrm{O}} & \text { Output Voltage of Position Sensor } \\ \mathrm{V}_{\mathrm{O}} & \text { Opamp Output Terminal Voltage } \\ \mathrm{w}_{\mathrm{H}} & \text { Initial Voltage } \\ \mathrm{w}_{\mathrm{d}} & \text { Higher Order Mechanical Resonance } \\ \mathrm{w}_{\mathrm{D}} & \text { Notch Filter Damping Frequency } \\ \mathrm{w}_{\mathrm{p}} & \text { Lead Compensator Denominator Break Frequency } \\ \mathrm{w}_{\mathrm{S}} & \text { Parallel Resonance Frequency } \\ \mathrm{w}_{\mathrm{Z}} & \text { Series Resonance Frequency } \\ \mathrm{Z}_{\mathrm{A}} & \text { Lead Compensator Numerator Break Frequency } \\ \Theta & \text { Actuator Input Impedance }\end{array}$




\section{INTRODUCTION}

In this thesis piezoelectric actuators are used to produce motion for an electro-optical scanning mirror system. Piezoelectric actuators are electromechanical transducers that produce motion with an applied electrical voltage. The displacement of the actuators is proportional to the applied voltage in their linear range of motion. In this scanning mirror system, piezoelectric benders are used to move the mirror. These are solid-state devices in that they produce motion without any moving parts such as gears, shafts or pulleys inherent in most motor-driven position control systems.

This thesis extends the work of Tomasetti [1], which provided a system that had a nine percent steady state error to a step input and a dynamic response of $3 \varnothing \varnothing \mathrm{Hz}$ bandwidth. The purpose of this thesis is to increase the control loop used from a "type ø" to a "type 1". This reduces the steady-state positional error for a step input to zero, while yielding finite non-zero steady state ramp error. A position sensor similar to that used in [1], but which has been modified to minimize drift due to temperature variations and $\mathrm{RF}$ noise, monitors the mirror position and generates a voltage proportional to the mirror's angular deflection. 
The piezoelectric actuator is an electrically capacitive energy storage element. This thesis is based on the fact that when the actuator is placed in the feedback path of an operational amplifier, a free integrator is introduced into the forward path of the control loop, thereby classifying it as a type one control system. As with a capacitor placed in the feedback path of an operational amplifier, the output of the operational amplifier will be the integral of the input reference voltage. Since the output voltage of the operational amplifier will be the applied voltage to the actuator, this causes the actuator displacement to be the integral of the applied reference voltage (since displacement of the actuator is proportional to applied voltage).

A type one control system removes hysteresis inherent in the actuator with the loop closed. Hysteresis is present to the extent that when a voltage is applied to the actuator (with no feedback) and then removed, the actuator does not return to the exact position it had prior to applying the voltage.

With the position sensor, the displacement can be fed back to a summing junction for closed loop position control. The essentially infinite loop gain at DC "forces" the steady state error to zero. In the Tomasetti prototype, the forward path gain at DC was ten with unity feedback. Therefore, the steady state error was 
appróximately nine percent (since error is unity divided by one plus the loop gain). Pavlinko [7] presented a method of increasing system type by introducing a separate integrator in the forward path and driving the actuator in the same manner as Tomasetti. His method was not built or tested.

This thesis begins by presenting the theory of operation for piezoelectric benders. A circuit model for the piezoelectric is presented and analyzed for the case in which it occupies the feedback path of the operational amplifier. The results of the analysis are used in all subsequent analyses. Compensation for mechanical resonances and the design procedures for the compensated plant are also presented. A description of the operation of the position sensor is given. Finally, the system is compared with the model used in the analysis and with the Tomasetti prototype. 


\section{PIEZOELECTRIC ACTUATORS}

This chapter presents a brief description of the general principles of piezoelectric actuation and gives the basic approach for producing mirror scanning motion using piezoelectric benders.

In general, a piezoelectric device is typically composed of a ceramic material that deforms when an electric potential (field) is applied, or causes an electric potential to be developed when it is deformed. The amount of deformation for a given applied field (sensitivity) is a function of the material. The piezoelectric material used in this thesis is PZT-5B (composed of lead, zirconium, and titanium) and has a high motion sensitivity.

To gain its piezoelectric properties, the actuator has to first be molded to the desired shape and allowed to dry. Then electrodes are applied by either electroplating, vacuum deposition, or conductive epoxy [5]. Now the material is heated to its Curie Point, the characteristic temperature at which the ceramic loses its piezoelectric properties [8]. While at this temperature, a high DC voltage is applied to the electrodes of the device. The unbalanced electrical dipoles of the ceramic's molecules will align in the direction of the applied field, as they 
are somewhat free to move at this temperature. The device is then allowed to cool with the voltage still applied so that the molecules are restrained in the orientation of the applied field [5].

When the piezoelectric device has a DC voltage applied to its electrodes, it will expand (or contract) longitudinally in the direction of the applied field and contract (or expand) transversely in parallel with the electrodes applying the field, dependent upon the polarization of the material and the polarity of the applied voltage.

The piezoelectric devices used in this thesis are known as benders, producing strain perpendicular to the electrode surface normal [1]. These devices are normally bonded to a thin metal vane, usually brass. This produces a bending mode with applied voltage causing a deformation similar to the bimetal strip in which one metal expands more than the other with a temperature increase. When only one ceramic body (plate) of material is mounted on the metal vane, the configuration is called a monomorph [5].

Two ceramic plates of material on opposite sides of the vane form a bimorph. "Bimorph" is a registered trademark of the Vernitron Piezoelectric Division [8]. The two plates are oppositely polarized, so that applied voltage causes them to deform in opposite directions [8]. This produces larger displacements than the monomorph. A 
bimorph is shown in Figure 1 illustrating the deformation due to an applied voltage.

In the scanning mirror application, two bimorphs are cantilever mounted as shown in Figure 2. A small mirror is mounted on the free ends of the benders using double-sided adhesive foam tape as hinges. These hinges allow motion of the mirror and benders without placing excessive stress on either. The benders are mounted and wired so that an applied voltage will cause deflections opposite each other. This deflection of the benders causes an angular deflection of the mirror as shown in the figure.

Also shown in the figure are the inductive coil pickups for the position sensor. The sensor is discussed in Chapter 7 . 


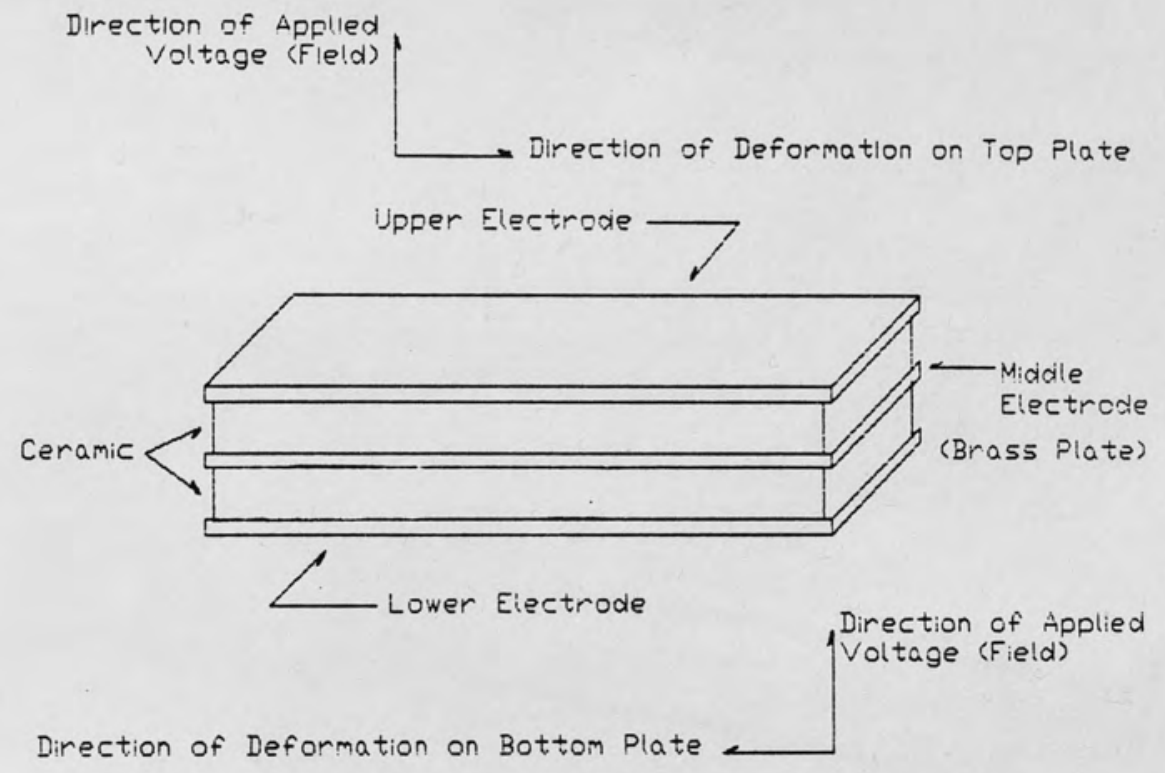

Figure 1. Bimorph Piezoelectric Actuator.

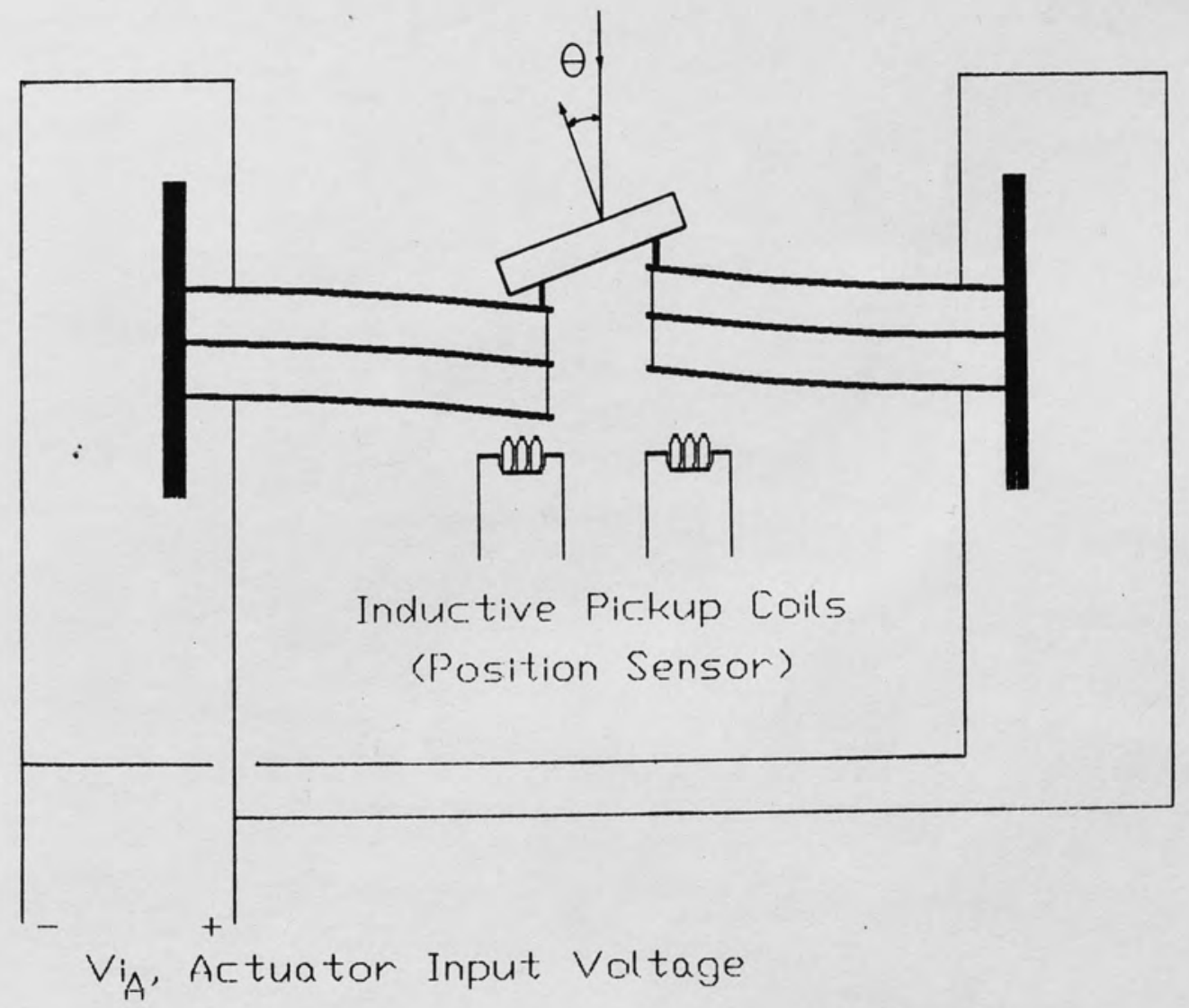

Figure 2. Bimorph Actuated Scanning Mirror System. 


\section{MODELING AND ANALYSIS}

This chapter presents the development of the actuator plant model and then analyzes the system for controlling the plant. It begins with a lower order actuator model accounting for a lower order resonance which describes the output of the physical system as a voltage proportional to the actuator's angular displacement for a given input voltage. The component parameters of the model are determined and then the model is placed in the opamp's feedback path to find the open position loop response. The output of the model is then fed back to the summing junction to close the loop and determine the closed loop response.

An electromechanical scale factor is added to the model to relate the model output voltage to the actuator angular displacement. This model is then placed in the opamp's feedback path and the closed loop response determined.

Finally, the model is "upgraded" to account for a higher order resonance by determining the higher order model parameters that describe the observed high frequency response of the actuator. This model is then placed in the feedback path of the opamp and both the open and closed loop responses determined. 
Determination of Lower order Model Parameters

The model of the piezoelectric actuator accounting for the first mode of vibration is shown in Figure 3. The transfer function for the model is as follows:

$$
\begin{aligned}
\operatorname{Ta}_{L}(s) & =\frac{\mathrm{Vo}_{\mathrm{A}}}{\mathrm{Vi}_{\mathrm{A}}} \\
& =\frac{1}{\mathrm{~L}_{\mathrm{m}} \mathrm{C}_{\mathrm{m}} \mathrm{s}^{2}+\mathrm{R}_{\mathrm{m}} \mathrm{C}_{\mathrm{m}} \mathrm{s}+1} \\
& =\frac{1}{\mathrm{~s}^{2} / \mathrm{w}_{\mathrm{s}}^{2}+\mathrm{s} /\left(\mathrm{Q}_{\mathrm{s}} \mathrm{w}_{\mathrm{s}}\right)+1}
\end{aligned}
$$

where $L_{m}, C_{m}$ and $R_{m}$ are the electrical equivalents of mechanical inductance, capacitance and resistance, respectively. The series resonance frequency and series resonance quality factor are $\mathrm{w}_{\mathrm{s}}$ and $\mathrm{Q}_{\mathrm{s}}$, respectively.

The output voltage of the low order model is proportional to the angular position of the actuator. When the actuator is placed in the feedback path of an opamp, the output voltage of the opamp is the input voltage to the actuator, i.e.,

$$
\mathrm{Ta}_{L}(s)=\frac{\mathrm{Vo}_{\mathrm{A}}}{\mathrm{Vi}_{\mathrm{A}}} \underset{\mathrm{Vo}}{\mathrm{Vo}}
$$

where $V i_{A}=V_{O}$, and $\theta$ is the actuator's angular displacement.

The input impedance of the actuator, obtained by simple circuit analysis, is determined to be: 


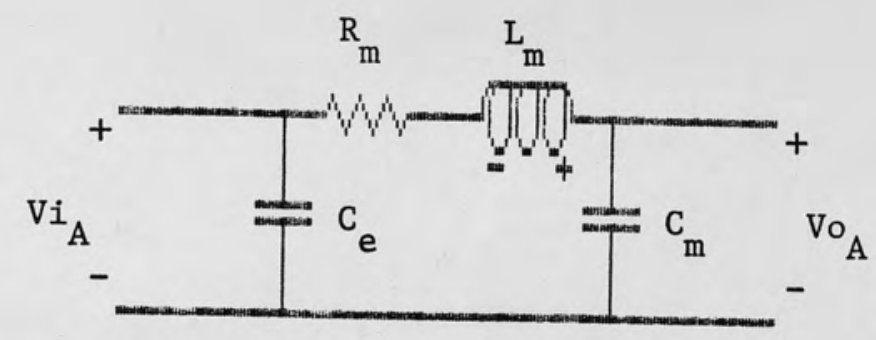

Figure 3. Actuator Lower Order Model.

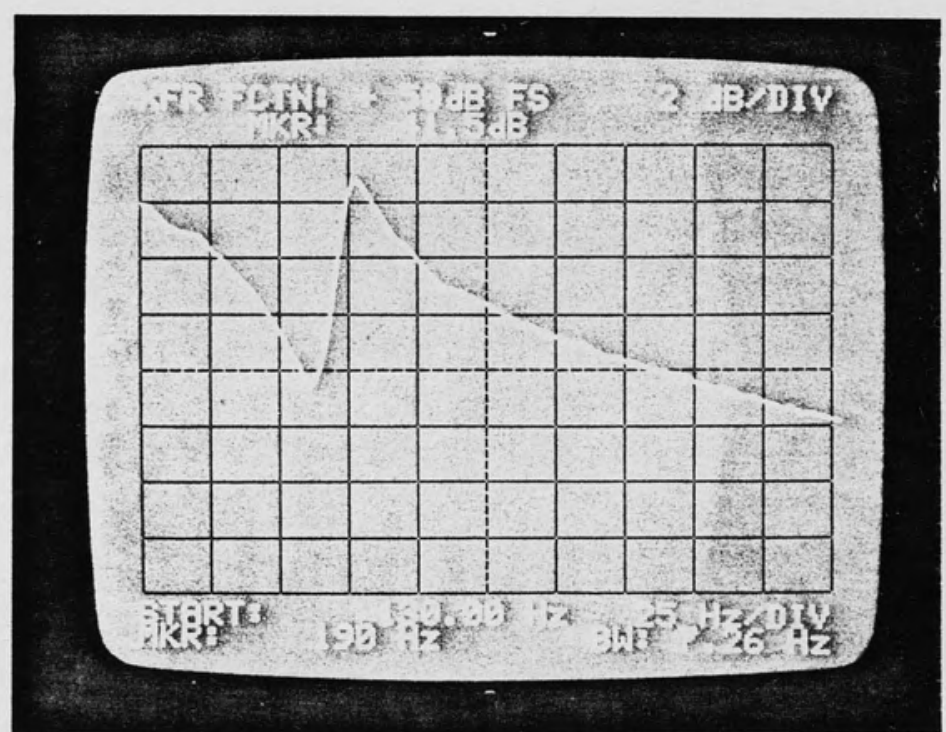

Figure 4. Actuator Input Impedance Photograph.

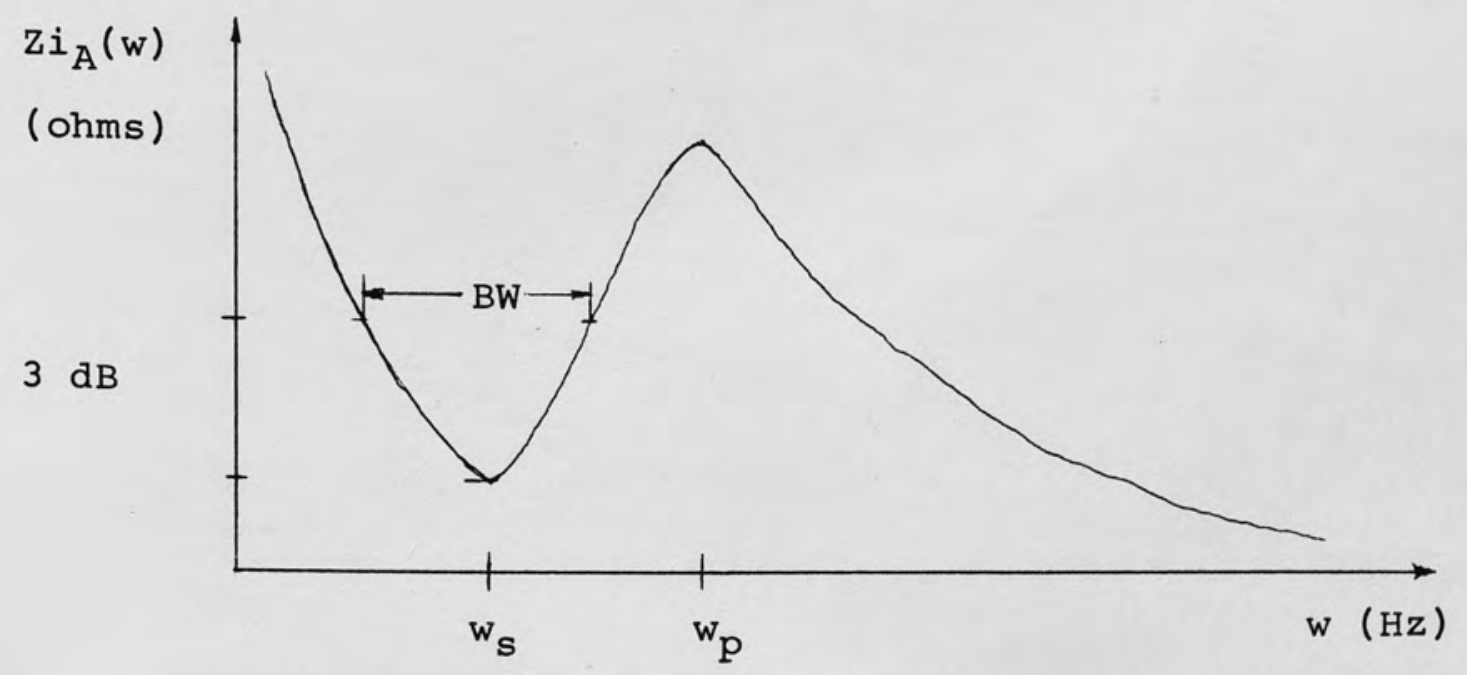

Figure 5. Actuator Input Impedance Graph. 


$$
\begin{aligned}
& z i_{A}=\frac{L_{m} C_{m} s^{2}+R_{m} C_{m} s+1}{C_{T} s\left[\frac{C_{e} C_{m}}{C_{T}} L_{m} s^{2}+\frac{C_{e} C_{m}}{C_{T}} C_{m}+1\right]} \\
& =\frac{s^{2} / w_{s}^{2}+s /\left(Q_{s} w_{s}\right)+1}{C_{T} s\left(s^{2} / w_{p}^{2}+s /\left(Q_{p} w_{p}\right)+1\right)}
\end{aligned}
$$

where

$$
\mathrm{C}_{\mathrm{T}}=\mathrm{C}_{\mathrm{e}}+\mathrm{C}_{\mathrm{m}} \text {. }
$$

The parallel resonance frequency and parallel resonance quality factor are $w_{p}$ and $Q_{p}$, respectively.

Using a spectrum analyzer, the actuator input impedance was determined as a function of frequency and plotted as shown in Figure 4.

The electrical capacitance, Ce, can be directly measured using a capacitance meter. As shown in Figure 5, $w_{s}$ is the frequency where the local valley occurs and $w_{p}$ is the frequency where the local peak occurs. $Q_{s}$ is determined by finding the $+3 \mathrm{~dB}$ frequencies on either side of $\mathrm{w}_{\mathbf{s}}$. The difference between them is the bandwidth. Dividing $w_{s}$ by this bandwidth yields

$$
Q_{s}=\frac{\mathrm{w}_{\mathrm{s}}}{\mathrm{BW}}
$$

where

$$
B W=f_{u}^{3 d B_{-}} f_{1}^{3 d B}
$$

Equating corresponding coefficients in (1) and (2), we find that: 


$$
\frac{1}{w_{s}^{2}}=L_{m} C_{m} \quad \text { and } \quad \frac{1}{w_{p}^{2}}=L_{m} \frac{C_{e} C_{m}}{C_{e}+C_{m}}
$$

This leads to the relationship:

$$
c_{m}=c_{e} \quad\left[\frac{w_{p}^{2}}{-\frac{p}{2}-}-1\right] \text {. }
$$

The mechanical inductance and resistance can be found from the following relationships:

$$
\frac{1}{\mathrm{w}_{\mathrm{s}}^{2}}=\mathrm{L}_{\mathrm{m}} \mathrm{C}_{\mathrm{m}} \quad \text { so } \quad \mathrm{L}_{\mathrm{m}}=\frac{1}{\mathrm{C}_{\mathrm{m}} \mathrm{w}_{\mathrm{s}}^{2}}
$$

and

$$
\frac{1}{\mathrm{Q}_{\mathrm{s}} \mathrm{w}_{\mathrm{s}}}=\mathrm{R}_{\mathrm{m}} \mathrm{C}_{\mathrm{m}} \quad \text { so } \quad \mathrm{R}_{\mathrm{m}}=\frac{1}{\mathrm{C}_{\mathrm{m}} \mathrm{Q}_{\mathrm{s}} \mathrm{w}_{\mathrm{s}}}
$$

The spectrum analyzer trace yielded the following information:

$$
\begin{aligned}
& \mathrm{w}_{\mathrm{s}}=1194 \mathrm{rad} / \mathrm{sec}(190 . \varnothing \mathrm{Hz}) \\
& \mathrm{w}_{\mathrm{p}}=1289 \mathrm{rad} / \mathrm{sec}(2 \varnothing 5.2 \mathrm{~Hz}) \\
& \mathrm{BW}=33.6 \mathrm{~Hz} \\
& \mathrm{Q}_{\mathrm{s}}=5.66 \\
& \mathrm{Q}_{\mathrm{p}}=6.11 .
\end{aligned}
$$

The following values were determined:

$$
\begin{aligned}
& C_{e}=42.7 \mathrm{nfd} \text { (direct measurement) } \\
& C_{m}=7.11 \mathrm{nfd} \\
& L_{m}=98.7 \text { henries } \\
& R_{m}=20834 \text { ohms. }
\end{aligned}
$$


Lower Order Model Open Loop Transfer Function

The model can now be placed in the feedback path of an opamp and the actuator response determined. As shown in Figure 6 , the response was initially determined without any positional feedback from actuator output $\left(\mathrm{Vo}_{\mathrm{A}}\right)$. This will be referred to as the open loop response. The following relationship is easily derived:

$$
\frac{\mathrm{Vo}_{\mathrm{O}}}{\mathrm{v}_{\mathrm{r}}}=\frac{-\mathrm{Zi}}{\mathrm{R}_{\text {in }}}
$$

Substituting (2) into (3) leads to the relationship:

$$
\frac{\mathrm{Vo}_{\mathrm{O}}}{\mathrm{V}_{\mathrm{r}}}=\frac{-\left(\mathrm{s}^{2} / \mathrm{w}_{\mathrm{s}}^{2}+\mathrm{s} /\left(\mathrm{Q}_{\mathrm{s}} \mathrm{w}_{\mathrm{s}}\right)+1\right)}{\mathrm{R}_{\mathrm{in}} \mathrm{C}_{\mathrm{T}} \mathrm{s}\left(\mathrm{s}^{2} / \mathrm{w}_{\mathrm{p}}^{2}+\mathrm{s} /\left(\mathrm{Q}_{\mathrm{p}} \mathrm{w}_{\mathrm{p}}\right)+1\right)}
$$

It is now necessary to relate the actuator model output voltage (which is proportional to the actuator angular position, $\boldsymbol{\theta}$, and position sensor voltage, $v_{p}$ ) to the input reference voltage, i.e.,

$$
\frac{\theta}{v_{r}} \infty \underset{\frac{v_{p}}{v_{r}}}{-\infty} \infty \frac{\mathrm{vo}_{A}}{v_{r}}
$$

Using $\mathrm{Vo}_{\mathrm{O}}=\mathrm{Vi}_{\mathrm{A}^{\prime}}$

$$
\begin{aligned}
\frac{\mathrm{Vo}_{\mathrm{A}}}{\mathrm{V}_{\mathrm{r}}} & =\frac{\mathrm{Vo}_{\mathrm{A}}}{\mathrm{Vi}_{\mathrm{A}}} * \frac{\mathrm{Vo}_{\mathrm{O}}}{\mathrm{V}_{\mathrm{r}}} \\
& =\mathrm{Ta}_{L}(\mathrm{~s}) * \frac{\mathrm{Vo}_{\mathrm{O}}}{\mathrm{v}_{\mathrm{r}}}
\end{aligned}
$$

substituting (4) into (5) yields the following relationship: 


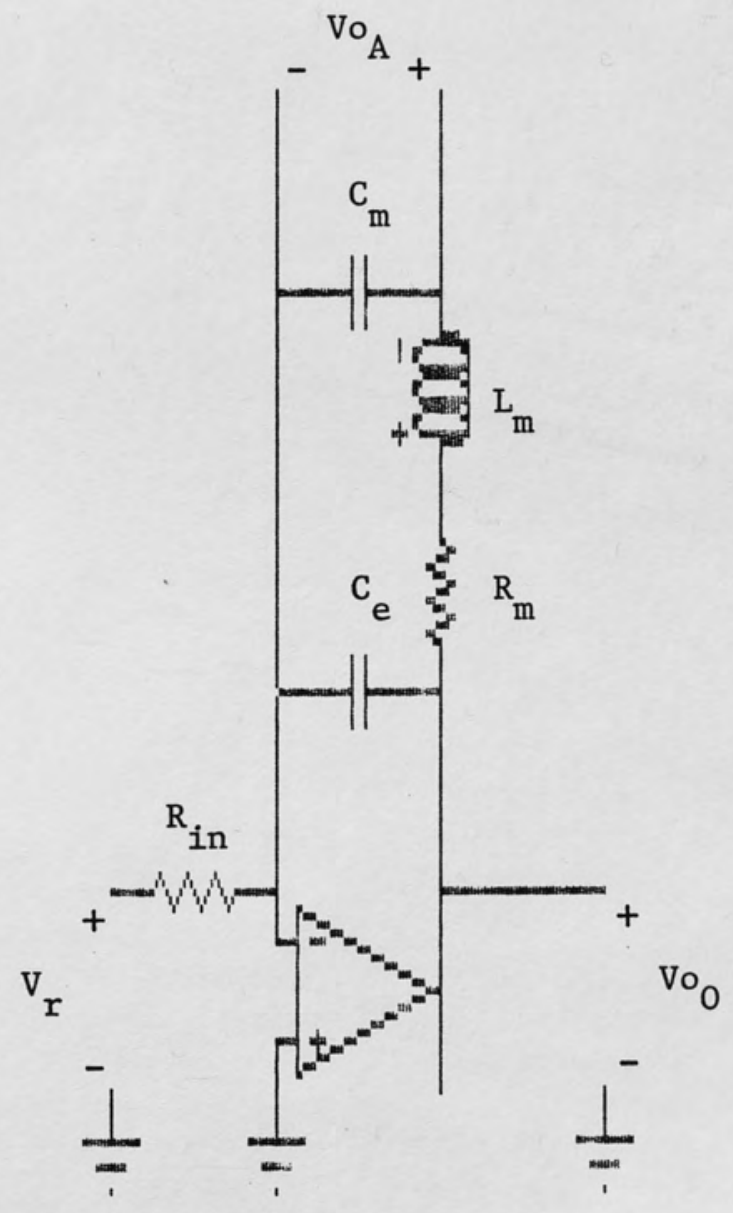

Figure 6. Open Loop Lower Model in Feedback Path. 


$$
\mathrm{T}_{\mathrm{OL}}(\mathrm{s})=\frac{\mathrm{Vo}_{\mathrm{A}}}{\mathrm{V}_{\mathrm{r}}}=\frac{-1}{\mathrm{R}_{\text {in }} \mathrm{C}_{\mathrm{T}} \mathrm{s}\left(\mathrm{s}^{2} / \mathrm{w}_{\mathrm{p}}^{2}+\mathrm{s} /\left(\mathrm{Q}_{\mathrm{p}} \mathrm{w}_{\mathrm{p}}\right)+1\right)}
$$

where $\mathrm{T}_{\mathrm{OL}}(\mathrm{s})$ is the open position loop transfer function for the lower order system model. The proportionality constant $K_{\Theta}$, relating the actuator's angular output displacement, in radians, to the actuator's input voltage will be determined in the next section.

\section{Lower Order Model Closed Loop Transfer Function}

Now, with the loop closed, the closed-loop transfer function is derived and the corresponding block diagram constructed. In Figure $7, \mathrm{Vo}_{\mathrm{A}}$ is fed back to the summing junction of the opamp through a feedback resistor, $R_{f}$. The transfer function can be derived from the following:

and

$$
\mathrm{Vo} \mathrm{O}_{0}=-\mathrm{Zi}_{\mathrm{A}} *\left[\frac{\mathrm{V}_{\mathrm{r}}}{\mathrm{R}_{\mathrm{in}}}+\frac{\mathrm{Vo}_{\mathrm{A}}}{\mathrm{R}_{\mathrm{f}}}\right]
$$

$$
\mathrm{Ta}_{L}(s)=\frac{\mathrm{Vo}_{\mathrm{A}}}{\mathrm{Vi}}=\frac{\mathrm{Vo}_{\mathrm{A}}}{\mathrm{Vo}}
$$

This leads to the following expressions:

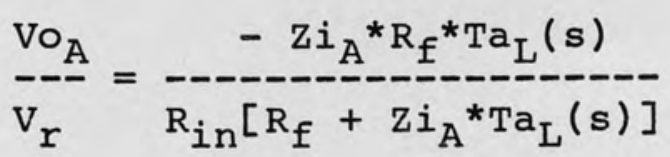

$$
\begin{aligned}
& =\frac{-1}{R_{i n} C_{T} s\left(s^{2} / w_{p}^{2}+s /\left(Q_{p} w_{p}\right)+1\right)+R_{i n} / R_{f}}
\end{aligned}
$$

This can be represented in block form as the following: 


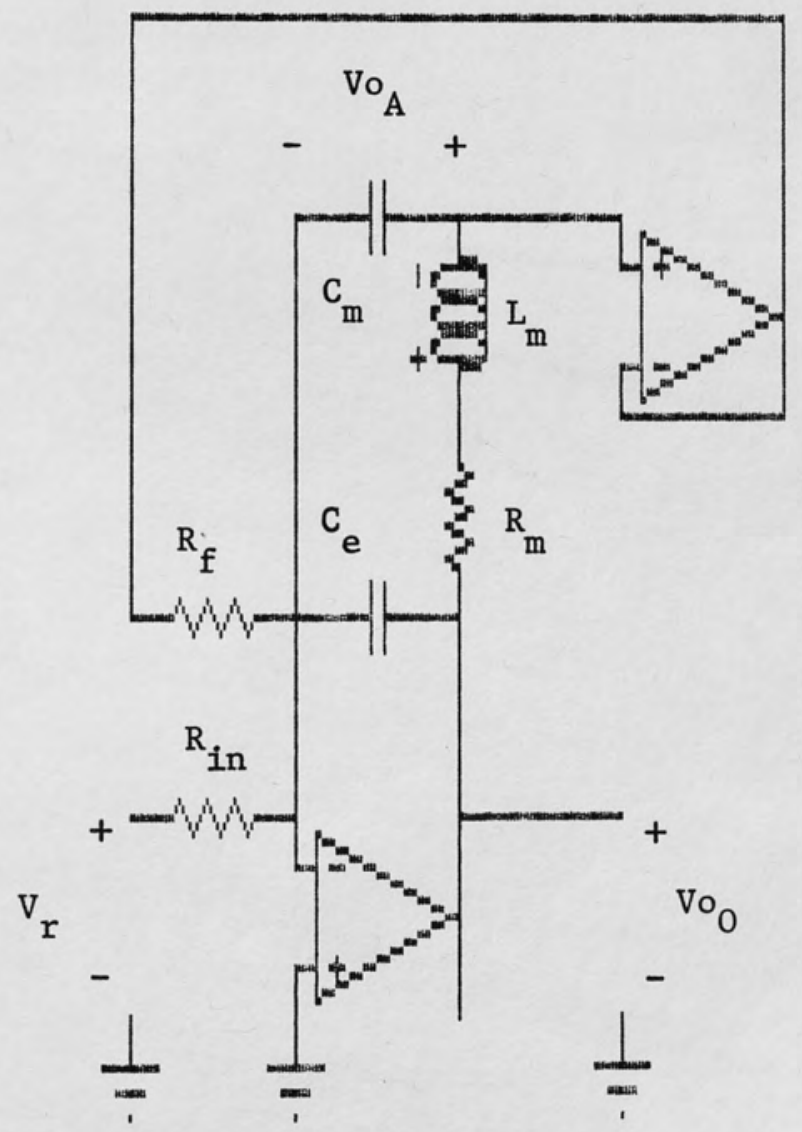

Figure 7. Closed Loop Lower Order Model in Feedback Path. 


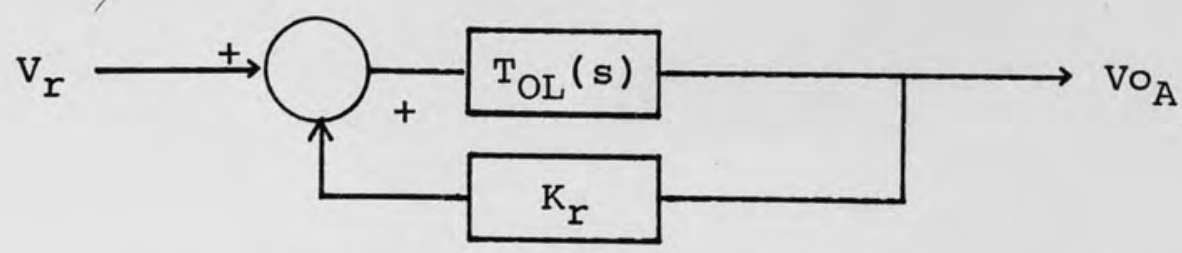

where $\mathrm{T}_{\mathrm{OL}}(\mathrm{s})$ is given by $(6)$ and $\mathrm{K}_{r}$ is the resistor ratio $R_{\text {in }} / R_{f}$. This ratio adjusts the loop gain and determines the placement of the closed loop poles. The positioning of these poles will be addressed in Chapter 4 . It can be seen that as $R_{f}$ approaches infinity, the open position loop transfer function $\mathrm{T}_{\mathrm{OL}}(\mathrm{s})$ is realized as expected.

\section{Electromechanical Scale Factor}

In order to represent the actual physical system, it is necessary to relate the actuator's physical output, $\theta$, to its input voltage. As shown in Figure 8 , this can be done by placing an electromechanical scale factor, $K_{\Theta}$, at the actuator's output, relating the output position to the model's output voltage. Using $\theta=\mathrm{K}_{\Theta} \mathrm{Vo}_{A}$ ' the transfer function for the actuator is as follows:

$$
\frac{\Theta}{\mathrm{Vi}_{\mathrm{A}}}=\frac{\mathrm{K}_{\boldsymbol{\theta}}}{\left(\mathrm{s}^{2} / \mathrm{w}_{\mathrm{s}}^{2}+\mathrm{s} /\left(\mathrm{Q}_{\mathrm{s}} \mathrm{w}_{\mathrm{s}}\right)+1\right)}
$$

$\mathrm{K}_{\Theta}$ was measured as $432 \mathrm{urad} / \mathrm{volt}$ with a very low frequency $(15 \mathrm{~Hz})$ input voltage to the actuator. Now with the actuator in the feedback path of the opamp as shown in Figure 9, the open position loop transfer function is obtained: 


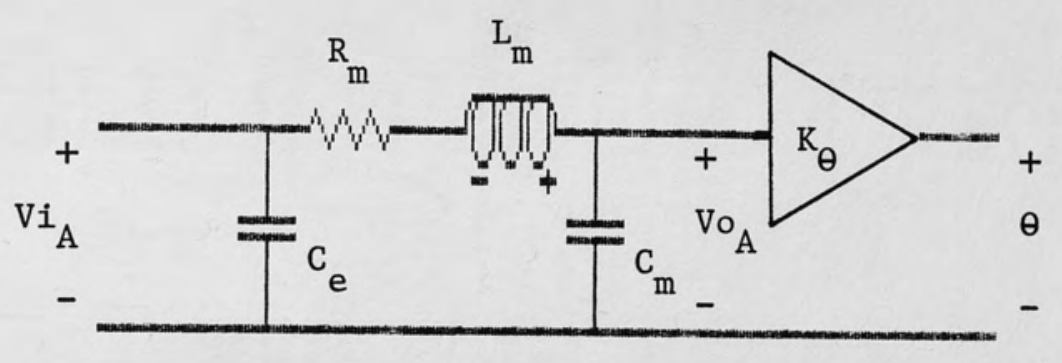

Figure 8. Model With Electromechanical Scale Factor.

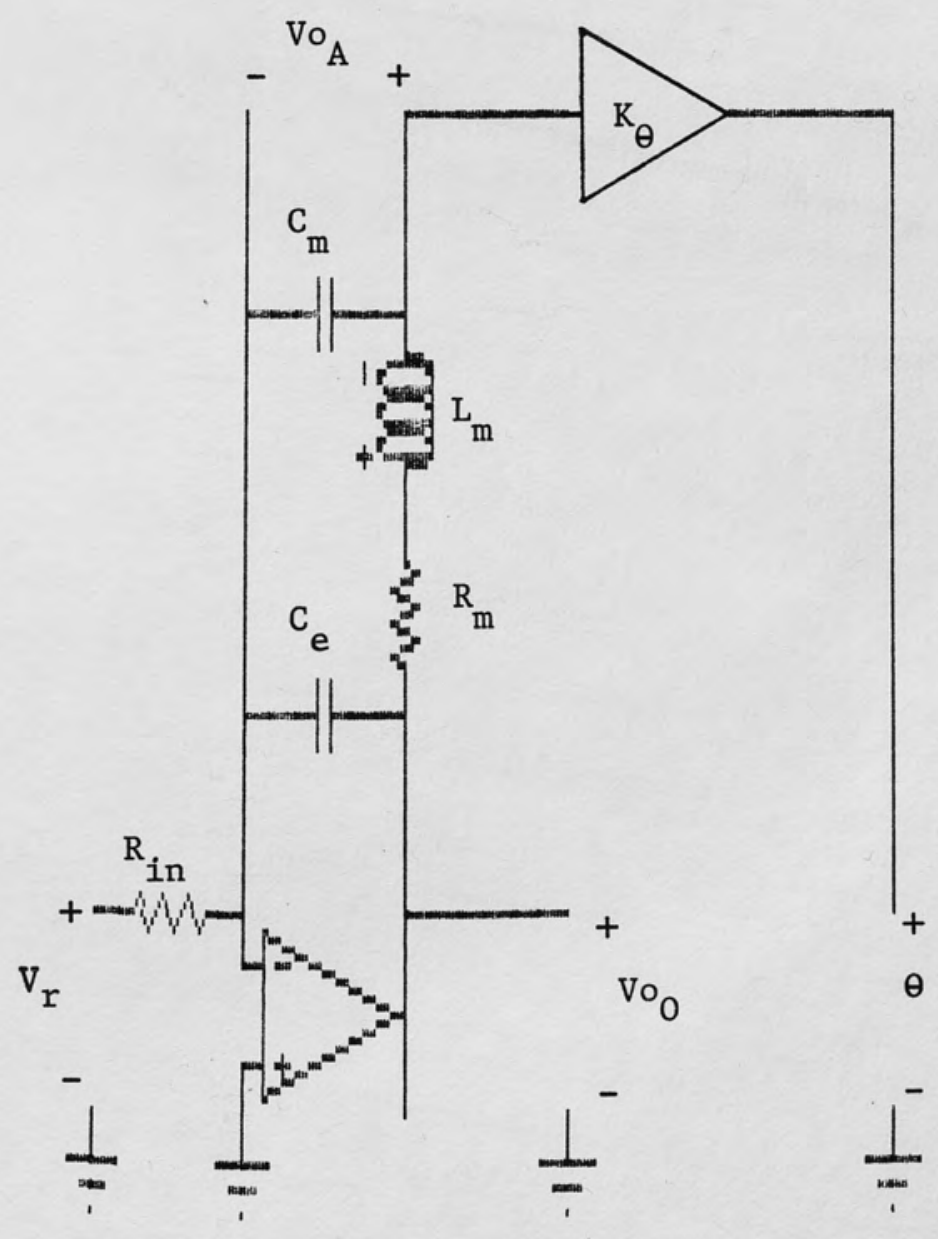

Figure 9. Model With Scale Factor in Feedback Path. 


$$
{ }_{\mathrm{OL}}^{\prime}(s)=\frac{\Theta}{\mathrm{v}_{\mathrm{r}}}=\frac{-\mathrm{K}_{\boldsymbol{\theta}}}{\mathrm{R}_{\text {in }} \mathrm{C}_{\mathrm{T}}\left(\mathrm{s}^{2} / \mathrm{w}_{\mathrm{p}}^{2}+\mathrm{s} /\left(\mathrm{Q}_{\mathrm{p}} \mathrm{w}_{\mathrm{p}}\right)+1\right)}
$$

This can be realized by the following block diagram:

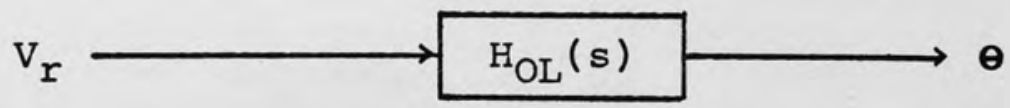

where $\mathrm{H}_{\mathrm{OL}}(\mathrm{s})$ is the lower order actuator open position loop transfer function.

\section{Lower Order Actuator Closed Loop Transfer Function}

With the position sensor (described in Chapter 7), the loop is closed and a voltage, $v_{p}$, proportional to actuator position, $\theta$, is fed back to the summing junction of the opamp. This is shown in Figure 1ø. The individual electromechanical scale factor, $\mathrm{K}_{\boldsymbol{\theta}}$, and position sensor scale factor, $K_{p}$, are represented as fixed gain amplifier stages. The gain sensitivity of the position sensor, $K_{p}$ ' is constant at 25 volts/rad. The following expression can be derived for the circuit:

$$
\mathrm{vo}_{O}=-\mathrm{zi}_{\mathrm{A}} *\left[\frac{\mathrm{v}_{\mathrm{r}}}{\mathrm{R}_{\text {in }}}+\frac{\mathrm{v}_{\mathrm{p}}}{\mathrm{R}_{\mathrm{f}}}\right] .
$$

The following relations also exist:

$$
\begin{aligned}
& \boldsymbol{\theta}=\mathrm{Vo}_{\mathrm{A}} * \mathrm{~K}_{\boldsymbol{\theta}} \\
& \mathrm{Vo}_{\mathrm{O}}=\mathrm{Vo}_{\mathrm{A}} * \mathrm{~T} \bar{a}_{\mathrm{L}}^{-1}(\mathrm{~s}) \\
& \mathrm{V}_{\mathrm{p}}=\mathrm{Vo}_{\mathrm{A}} * \mathrm{~K}_{\boldsymbol{\theta}} * \mathrm{~K}_{\mathrm{p}} \\
& \mathrm{K}_{1 \mathrm{p}}=\mathrm{K}_{\boldsymbol{\theta}} * \mathrm{~K}_{\mathrm{p}}=10.8 \mathrm{mV} / \mathrm{v} .
\end{aligned}
$$




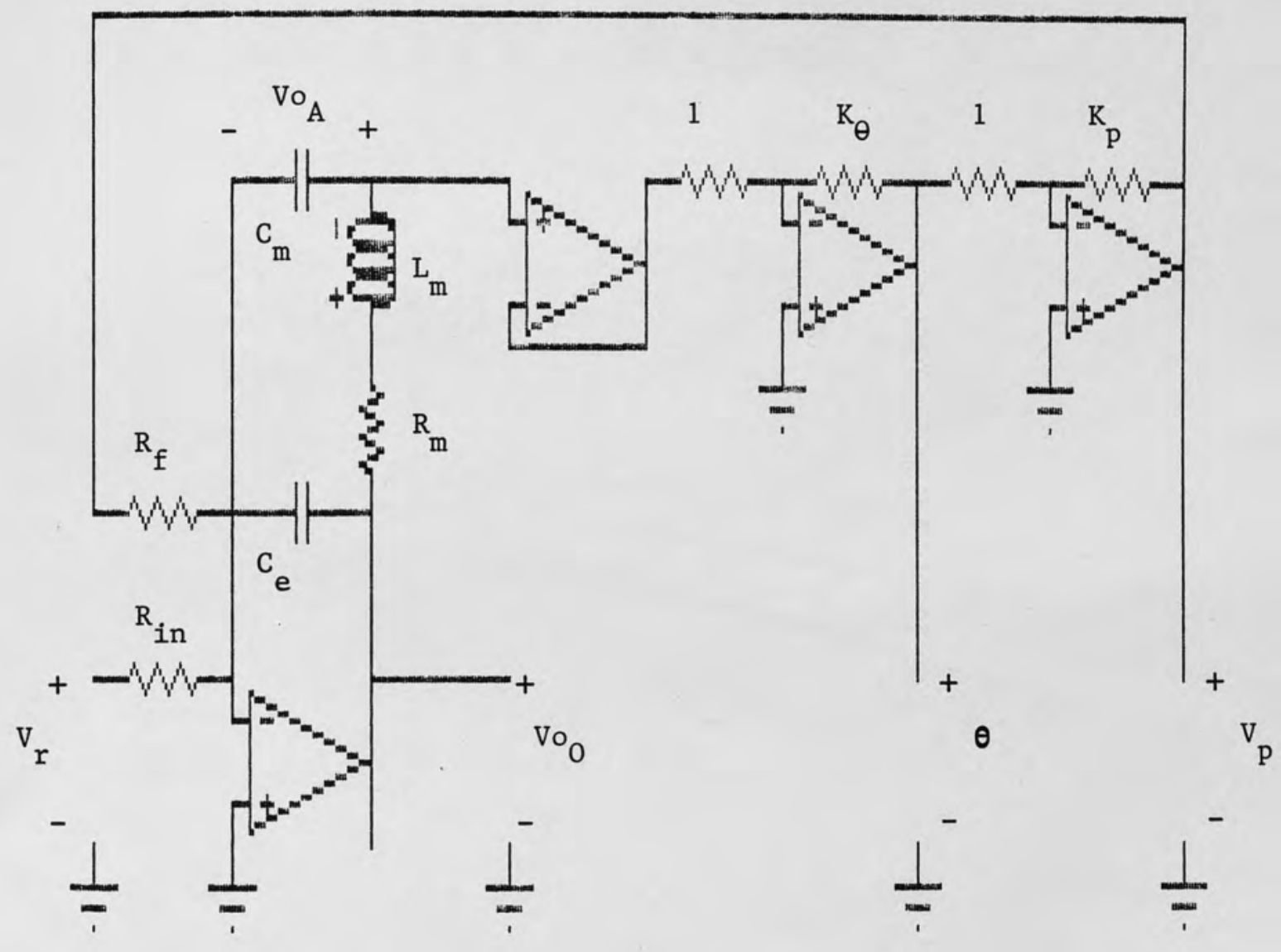

Figure 10. Closed Loop Low Order Plant Model.

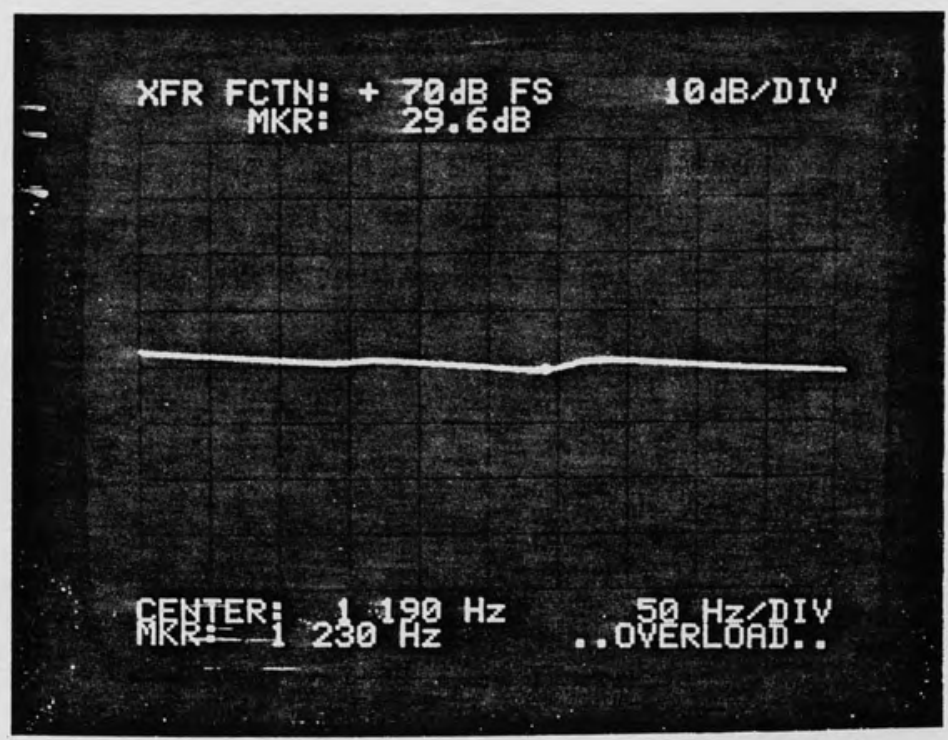

Figure 11. High order Input Impedance Photograph. 
Substituting these into (1ø) yields the following expression:

$$
\frac{\boldsymbol{\theta}}{\mathrm{v}_{\mathrm{r}}}=\frac{\mathrm{Zi}_{\mathrm{A}} \text { * } \mathrm{K}_{\boldsymbol{\theta}} \text { * } \mathrm{Ta}_{\mathrm{L}}(\mathrm{s})}{\mathrm{R}_{\mathrm{in}}\left[\mathrm{l}+\left(\mathrm{zi}_{\mathrm{A}} \text { * } \mathrm{K}_{\mathrm{lp}} \text { * } \mathrm{Ta}_{\mathrm{L}}(\mathrm{s})\right) / \mathrm{R}_{\mathrm{f}}\right]}
$$

This simplifies to the following equation:

$$
\frac{\Theta}{v_{r}}=\frac{-K_{\theta}}{R_{\text {in }} C_{T} s\left(s^{2} / w_{p}^{2}+s /\left(Q_{p} w_{p}\right)+1\right)+K}
$$

where

$$
K=K_{\boldsymbol{\theta}} * K_{p} * \frac{R_{\text {in }}}{R_{f}} .
$$

This leads to the following block diagram:

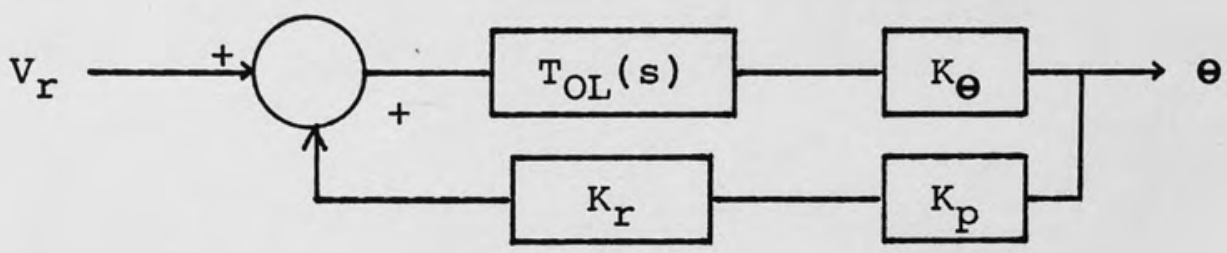

where $\mathrm{T}_{\mathrm{OL}}(\mathrm{s})$ is as defined in $(7)$.

In the actual plant, open loop dynamic characteristics followed the lower order model in gain and phase until about $25 \varnothing \mathrm{Hz}$. At frequencies above this a secondary mechanical resonance at approximately $11 \varnothing \emptyset \mathrm{Hz}$ was observed. However, as shown in Figure 11, from an impedance standpoint, no appreciable local valleys or peaks were found when the actuator's impedance was observed over this frequency range on the spectrum analyzer. This suggests modifying the actuator model by 
cascading another RLC resonant stage onto the model, this stage being decoupled from an impedance standpoint.

\section{Higher Order Model Parameters}

As shown in Figure 12, this cascaded RLC circuit must have a rather large input impedance so as not to load the lower order model stage. Component values were selected for the model such that the model's output voltage matched the actuator's observed mechanical output in gain and phase. The values also resulted in a large input impedance decoupled from the lower order stage. This results in changing the actuator's transfer function by adding a multiplying factor in the denominator of the lower order model's transfer function, i.e.,

$$
\begin{aligned}
& \operatorname{Ta}_{\mathrm{H}}(\mathrm{s})=\frac{\mathrm{Vo}_{\mathrm{A}}}{\mathrm{Vi_{A }}} \\
& =\left(s^{2} / w_{s}^{2}+s /\left(Q_{s} w_{s}\right)+1\right)\left(s^{2} / w_{H}^{2}+s /\left(Q_{H} w_{H}\right)+1\right)
\end{aligned}
$$

where

$$
\mathrm{w}_{\mathrm{H}}^{2}=\frac{1}{\mathrm{~L}_{\mathrm{H}} \mathrm{C}_{\mathrm{H}}}, \quad \mathrm{Q}_{\mathrm{H}} \mathrm{w}_{\mathrm{H}}=\frac{1}{\mathrm{R}_{\mathrm{H}} \mathrm{C}_{\mathrm{H}}}
$$

The input impedance of the actuator remains the same due to the non-loading of the higher order, high impedance, cascaded stage. This involves choosing $\mathrm{C}_{\mathrm{H}}$ small and finding the values of $R_{H}$ and $L_{H}$ which yield the observed $Q_{H}=14$ and $w_{H}=6849 \mathrm{rad} / \mathrm{sec}(1 \emptyset 9 \emptyset \mathrm{Hz})$. These 


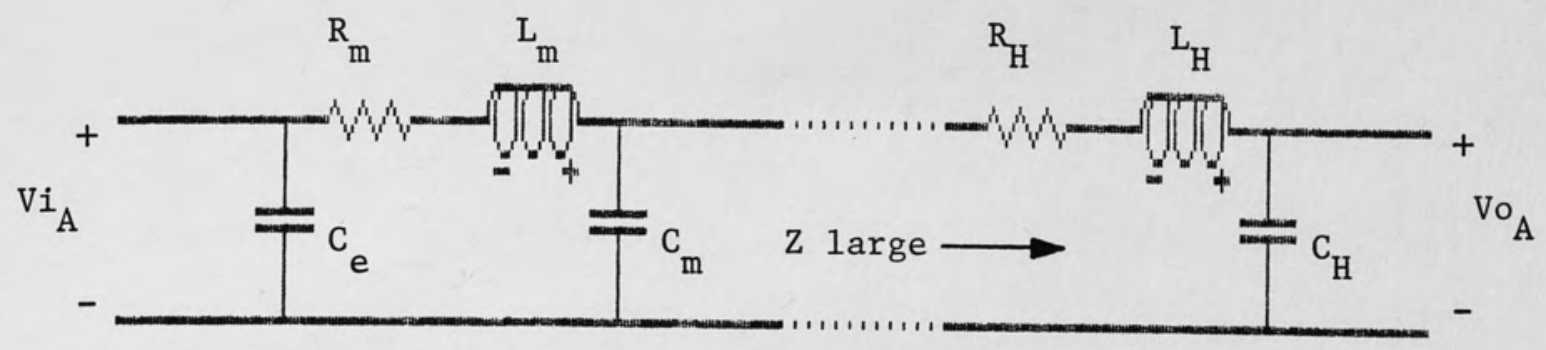

Figure 12. Higher Order Actuator Model.

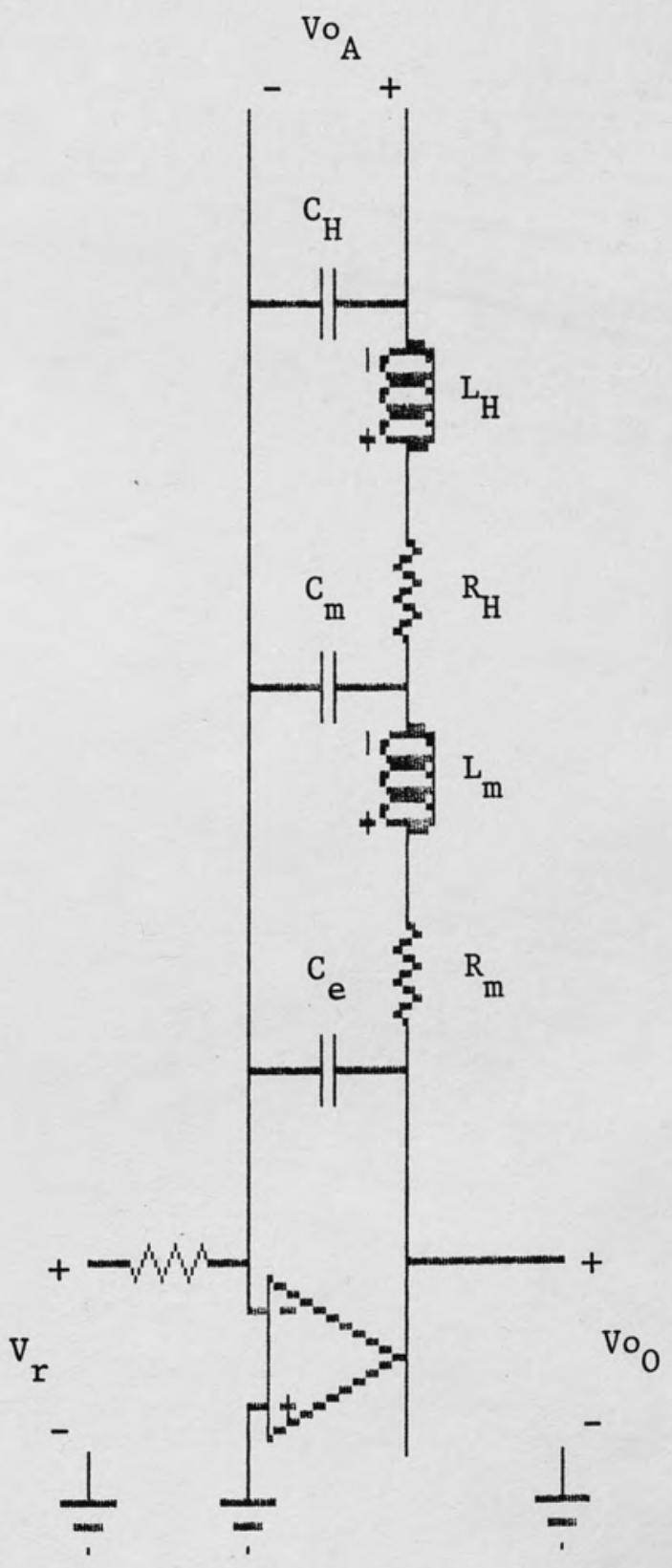

Figure 13. Open Loop Higher order Model in Feedback Path. 
are the values as determined by making $C_{H}$ a hundredth the size of $\mathrm{C}_{\mathrm{m}}$ :

$\mathrm{C}_{\mathrm{H}}=71.1 \mathrm{pfd}$

$\mathrm{L}_{\mathrm{H}}=3 \emptyset \emptyset$ henries

$\mathrm{R}_{\mathrm{H}}=1467 \varnothing \varnothing$ ohms.

To find the response with the higher order model in the feedback path of the opamp, the new actuator model transfer function, $\mathrm{Ta}_{\mathrm{H}}(\mathrm{s})$, and the original (since it has not changed) actuator impedance $\mathrm{Zi}_{\mathrm{A}}$, will be used in the analysis.

\section{Higher Order Model Open Position Loop Transfer Function}

As shown in Figure 13, the higher order model is placed in the feedback path of the opamp, and the open position loop transfer function is found. The procedure is analogous to that used for the lower order system. This yields the following expression:

$$
\frac{\mathrm{Vo}_{\mathrm{A}}}{\mathrm{V}_{\mathrm{r}}}=\frac{\mathrm{Vo}_{\mathrm{A}}}{\mathrm{Vi}_{\mathrm{A}}} * \frac{\mathrm{Vo}_{\mathrm{O}}}{\mathrm{V}_{\mathrm{r}}}=\mathrm{Ta}_{\mathrm{H}}(\mathrm{s}) * \frac{-\mathrm{Zi}_{\mathrm{A}}}{\mathrm{R}_{\mathrm{in}}}
$$

where $\mathrm{Vo}_{\mathrm{A}}=\mathrm{Vi}_{\mathrm{A}}$.

Substituting (2) and (12) into (13) we obtain:

$$
\mathrm{T}_{\mathrm{OH}}(\mathrm{s})=\stackrel{\mathrm{VO}_{\mathrm{A}}}{\mathrm{V}_{\mathrm{r}}}
$$


where $\mathrm{T}_{\mathrm{OH}}(\mathrm{s})$ is the higher order model's open position loop transfer function.

This can be represented in block diagram form as shown in the following:

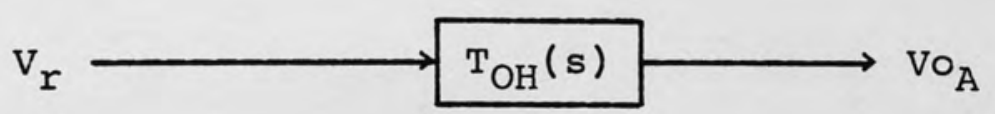

Higher Order Model Closed Loop Transfer Function

As shown in Figure 14, the electromechanical scale factor and position sensor are taken into account and the loop closed as before to determine the closed loop transfer function of the actuator plant. This figure shows actual model values and gain constants to use in simulating the system. The transfer function can be derived from the following:

$$
\mathrm{Vo}_{\mathrm{O}}=-\mathrm{zi}_{\mathrm{A}} * \underset{\mathrm{R}_{\text {in }}}{\left[\frac{\mathrm{V}_{\mathrm{r}}}{\mathrm{R}_{f}}\right.}+\frac{\mathrm{V}_{\mathrm{p}}}{]} .
$$

This expression results in the following equation:

$\boldsymbol{\theta}$

$\overline{v_{r}}$

$=\frac{R_{\text {in }} C_{T} s\left(s^{2} / w_{p}^{2}+s /\left(Q_{p} w_{p}\right)+1\right)\left(s^{2} / w_{H}^{2}+s /\left(Q_{H} w_{H}\right)+1\right)+K}{\left.R^{2}+1\right)}$

where

$K=K_{\Theta} * K_{p} * \frac{R_{\text {in }}}{R_{f}}$. 


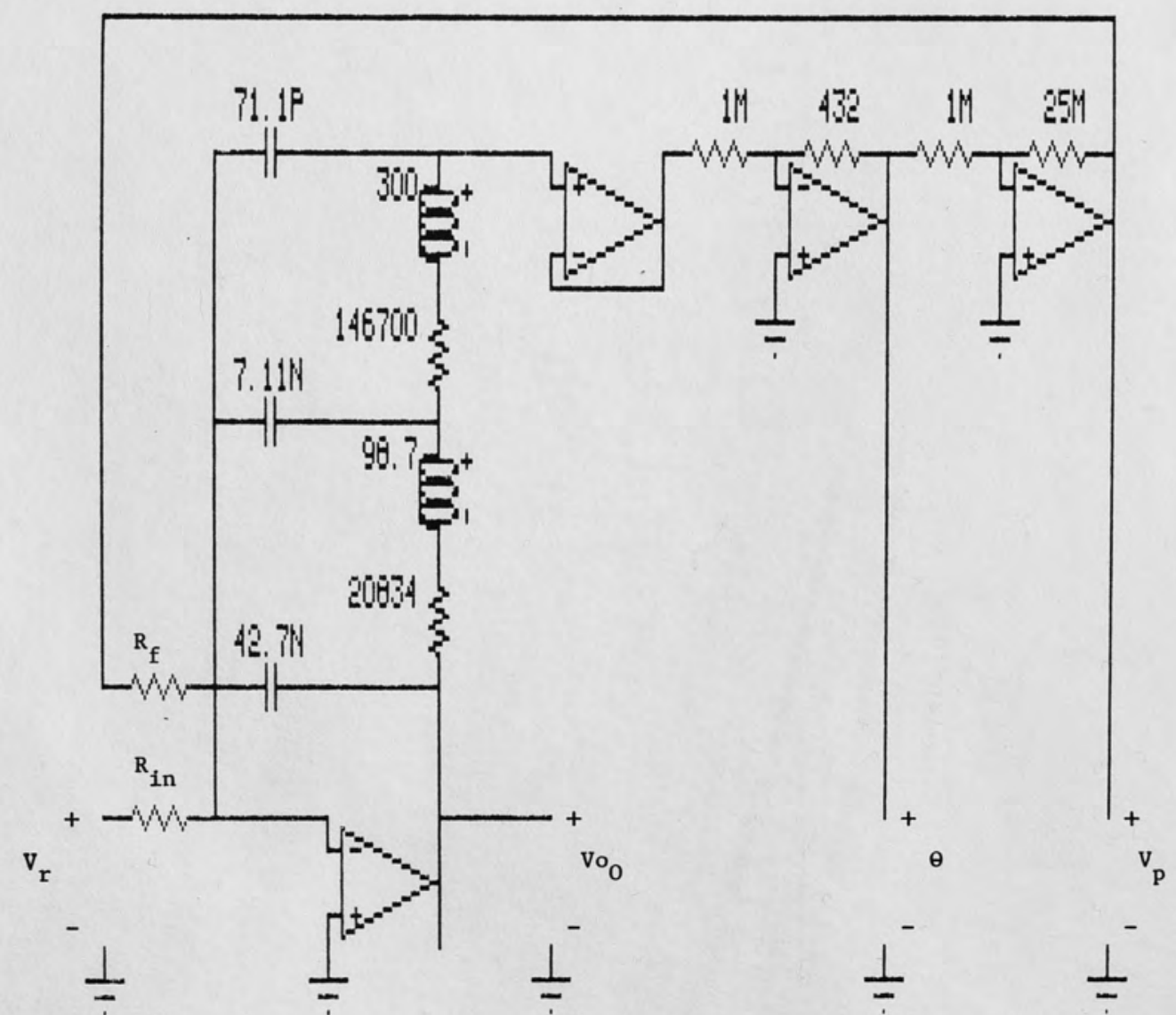

Figure 14. Closed Loop High Order Plant Mode1. 
This is the closed loop transfer function of the actuator with all important dynamic characteristics taken into account. In block diagram form this is shown as:

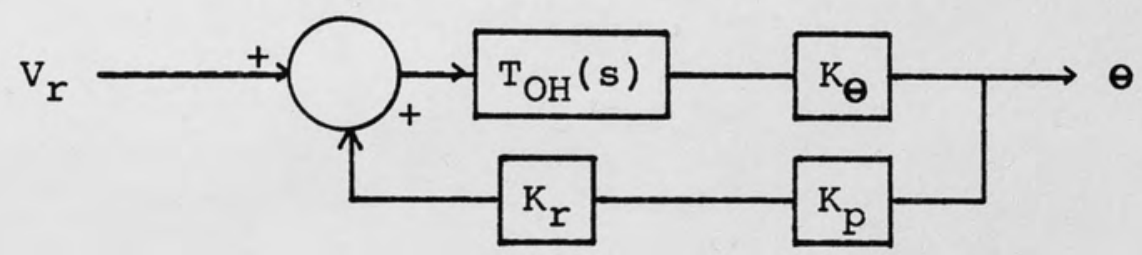

Adjustment of the loop gain must be made in order to satisfy stability and bandwidth specifications. Adjustment must also be made to the forward path gain to limit the steady state error to a ramp input at a desired maximum. These adjustments are discussed in the next chapter. 


\section{INITIAL DESIGN CONSIDERATIONS}

This chapter presents the design considerations for the uncompensated system. The closed loop pole locations necessary in order to satisfy specifications on stability and bandwidth are considered. DC gain and the steady state error criteria are also examined. The uncompensated system design is presented in general (no actual numerical values determined), taking into account the limitations on plant input resistance and opamp output current limitations.

\section{Steady State Error}

Since the control system has a free integrator in its forward path, it is classified as a type 1 system. Therefore, it will have zero steady state error to a step input and a constant steady state error to a ramp input. The ramp error depends on the reference input voltage slope and forward path gain of the free integrator. For larger sloped ramp inputs, larger steady state errors will occur. If the forward path gain is increased, however, this constant error is reduced. The following relationship determines the steady state error for a ramp input of $M_{1}$ (volts/sec), i.e., for the input $v_{r}=M_{1}{ }^{t}+v_{0}$, the resultant error is:

$$
\mathrm{E}_{1}=\mathrm{M}_{1} / \mathrm{K}_{1} \text {, }
$$


where $K_{1}$ is the forward path gain (or equivalently called the steady state ramp error coefficient, $\mathrm{K}_{\mathrm{v}}$ ) with units $\sec ^{-1}$, and $E_{1}$ is the error at the actuator model's output $\left(\mathrm{Vo}_{\mathrm{A}}\right)$ in volts.

For the actuator model, the integrator's forward path gain is as follows:

$$
\mathrm{K}_{1}=\frac{1}{\mathrm{R}_{\mathrm{in}} \mathrm{C}_{\mathrm{T}}}
$$

Thus, making $R_{\text {in }}$ smaller will increase the forward path gain, in turn reducing the steady state error. $C_{T}$ cannot be altered.

The actuator's angular displacement error can be found with the following relationship:

$$
\mathrm{E}_{\boldsymbol{\theta}}=\mathrm{E}_{1} * \mathrm{~K}_{\boldsymbol{\theta}^{\prime}}
$$

where $K_{\boldsymbol{\theta}}$ is the actuator's electromechanical scale factor, and $\mathrm{E}_{\boldsymbol{\theta}}$ is the difference between the desired actuator output and the actual actuator output. Obviously this output error cannot be expressed as a percent since the input (and output) are constantly changing with a ramp input.

From a design standpoint, limitations in opamp slew rate, size of the capacitive load $\left(C_{T}\right)$ and the size of the reference source impedance will determine the chosen value of $R_{\text {in }}$. These considerations will be addressed shortly in this chapter. 


\section{Gain}

Another consideration in choosing $\mathrm{R}_{\text {in }}$ is the overall DC gain, $K_{D C}$ of the actuator system. This can be found from the overall transfer function (by letting $s \rightarrow \emptyset$ ) and is as follows:

$$
\mathrm{K}_{\mathrm{DC}}=\frac{\mathrm{R}_{\mathrm{f}}}{\mathrm{K}_{\mathrm{p}} * \mathrm{R}_{\mathrm{in}}} \quad \text { (rad/volt) }
$$

Therefore, $R_{\text {in }}$ will determine the $D C$ gain for a given $R_{f}$ and $\mathrm{K}_{\mathrm{p}}$.

\section{Pole Placement}

Placement of the closed loop poles for stability purposes must also be considered. Factors that determine the placement of these poles can be found by examining the closed loop transfer function:

$$
\begin{aligned}
& \theta \\
& \mathrm{v}_{\mathrm{r}}
\end{aligned}
$$

where

$$
\mathrm{K}=\mathrm{K}_{\boldsymbol{\theta}} * \mathrm{~K}_{\mathrm{p}} * \frac{\mathrm{R}_{\mathrm{in}}}{-\mathrm{R}_{\mathrm{f}}}
$$

Dividing the numerator and denominator by $\mathrm{R}_{\text {in }} \mathrm{C}_{\mathrm{T}}$ yields: 
$\boldsymbol{\theta}$

$\overline{v_{r}}$

$$
=\frac{-K_{v} K_{\Theta}}{s\left(s^{2} / w_{p}^{2}+s /\left(Q_{p} w_{p}\right)+1\right)\left(s^{2} / w_{H}^{2}+s /\left(Q_{H_{H}}\right)+1\right)+K^{\prime}}
$$

where:

$$
K^{\prime}=\frac{K_{\theta^{K}} K_{p}}{R_{f} C_{T}}
$$

and

$$
\mathrm{K}_{\mathrm{v}}=\frac{1}{\mathrm{R}_{\text {in }} \mathrm{C}_{\mathrm{T}}}
$$

$\mathrm{K}^{\prime}$ is the overall adjustable loop gain and $\mathrm{K}_{\mathrm{V}}$ is the steady state ramp error coefficient. Thus the only adjustable parameters that affect the closed loop pole locations are the feedback resistance and the position sensor's gain.

Summarizing, the available parameters that affect system performance are the input and feedback resistors $\left(R_{i n}\right.$ and $R_{f}$ ) and the position sensor gain $\left(K_{p}\right)$. To achieve desired system performance, the (set of permissible) closed loop poles should be specified (determined by the overall adjustable loop gain, $\left.K^{\prime}\right)$.

Overall DC gain ( $K_{D C}$ ) and steady state error (determined by forward path gain, $\mathrm{K}_{l}$ ) should also be specified. Without any compensation, the three 
specifications (DC gain, stability and steady state error) that determine system performance are determined by three adjustable parameters: $R_{f}, R_{i n}$ and $K_{p}$. The values that meet the design specifications are determined next.

\section{Uncompensated System Design}

To determine the value of plant input resistance that sets the ramp error coefficient, the following relationship is used:

$$
\mathrm{R}_{\text {in }}=\mathrm{K}_{1} / \mathrm{C}_{\mathrm{T}^{\prime}}
$$

where $K_{1}$ is determined from the desired error for a given ramp input, i.e.,

$$
\mathrm{K}_{1}=\mathrm{M}_{1} / \mathrm{E}_{1} \text {, }
$$

for the ramp input voltage of slope $M_{1}$, and the desired error $E_{1}$.

Stability (pole placement) is determined by the overall adjustable loop gain, $K^{\prime}$. Once the desired range of $K^{\prime}$ is determined, the following determines the ratio of position sensor gain, $K_{p}$, and feedback resistance, $R_{f}$ :

$$
\frac{K_{p}}{-\underline{R_{f}}}=\frac{K^{\prime} * C_{T}}{K_{\Theta}}
$$

With this value determined, the overall DC gain, $K_{D C}$ is known since

$$
\mathrm{K}_{\mathrm{DC}}=\frac{\mathrm{R}_{\mathrm{f}}}{\mathrm{K}_{\mathrm{p}} * \mathrm{R}_{\mathrm{in}}}
$$


and the values of $R_{f}, R_{i n}$ and $K_{p}$ are determined by steady state error and stability criteria.

With the overall DC gain restricted to a value dependent on the stability and steady state error criteria, a cascaded attenuator or amplifier will be necessary for the desired overall gain. This is a minor consideration, as this can easily be obtained with a very basic straight gain amplifier (or attenuator) between the input reference voltage, $V_{r}$, and the system input.

\section{Plant Input Resistance Limitations}

As previously mentioned, $R_{\text {in }}$ affects the steady state ramp error coefficient. Making $R_{i n}$ smaller increases the error coefficient, thereby decreasing the steady state error. Practical limitations should be taken into consideration on its size. Too small a value will significantly load the source and attenuate the desired input signal. The output limitations of the opamp must also be considered. If the desired ramp output is "steeper" than the opamp's capabilities (slew rate), then decreasing $R_{\text {in }}$ will not decrease the steady state error and it could grow in a boundless fashion with continued input.

\section{Opamp Output Current Limitations}

Opamp output current limitations also affect the steady state error. For example, with a capacitive load, the 
maximum rate of change at the opamp output is

$$
d V \circ_{O} / \operatorname{dt}(\max )=\frac{1}{\mathrm{C}_{\mathrm{T}}} \text { } * I \circ_{\mathrm{O}}(\max ),
$$

where $I_{O}(\max )$ is the maximum rated opamp output current. Thus with large capacitive loads, decreasing $R_{\text {in }}$ will not decrease the steady state error with inputs that attempt to drive the output at rates greater than the above evaluated expression.

Parameter values for achieving desired system performance could be selected if the locus of closed loop poles passed through a set of desirable locations. Unfortunately, the locus does not pass through any desirable locations. Therefore, compensation will be necessary to place the poles at the desired locations. This is the topic of the next chapter. 


\section{COMPENSATION}

The purpose of this chapter is to present the method of compensation for removing undesired poles from the open loop transfer function. The undesired mechanical resonance poles are cancelled out and replaced with a set of more desirable pole locations. This increases the bandwidth along with the stability of the closed loop system.

Presented first is the method of compensation for the lower order resonance. This is followed by the method of compensation for the higher order resonance, which is essentially the same as the method used for the lower order resonance.

Shown in Figure 15 is the set of all pole locations for all loop gain settings without any compensation. The two complex dominant poles nearest the right half complex plane and the pole at the origin are the poles of interest to design compensation for.

The complex dominant poles nearest the right half plane in the root locus plot of Figure 15 enter the right half plane at an overall adjustable loop gain of $2 \varnothing \emptyset \mathrm{sec}^{-1}$. The open loop damping ratio is $\emptyset . \varnothing 82$, and therefore closing the loop and setting the gain does not give any desirable pole locations. The physical system is inherently unstable when connected as shown in Figure 14. 


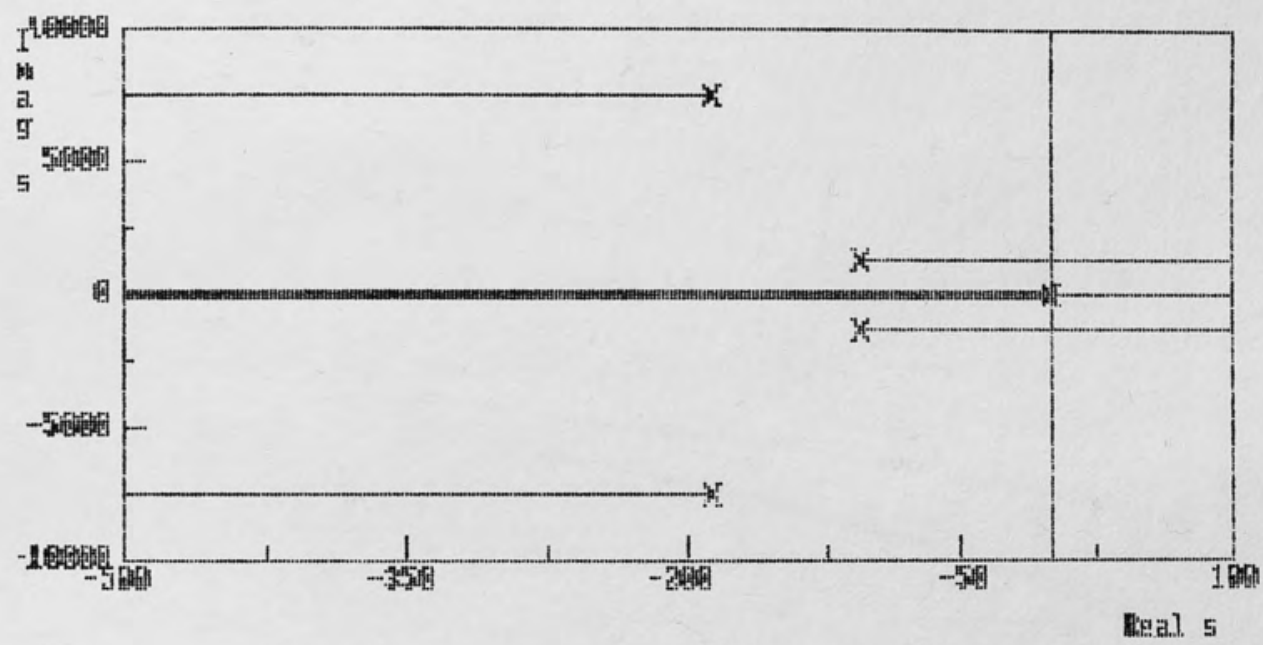

Figure 15. Root Locus of Uncompensated Plant.

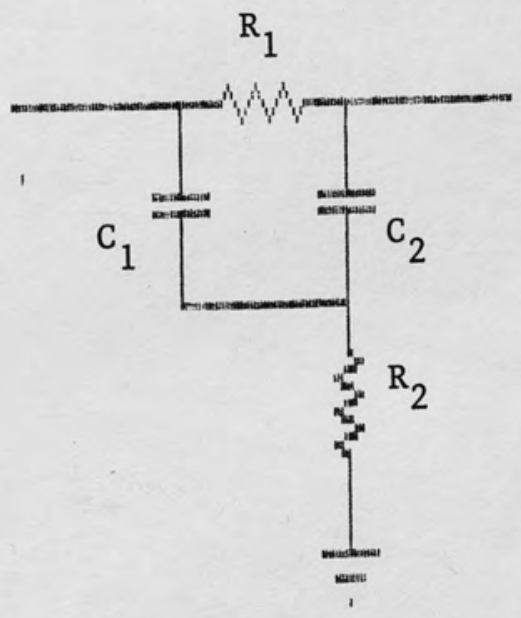

Figure 16. Biquadratic Notch Filter. 


\section{Lower Order Compensation}

The compensation for the lower order resonance, involving two compensating circuits, cancel the complex pole pair in the open loop transfer function involving $w_{p}$ and $e_{p}$. The circuits replace them with a pair of real, first order poles that allow sufficient physically realizable gain to be introduced in order to satisfy bandwidth and stability specifications.

\section{Lower Order Biquadratic Notch Filter}

A passive, bridged-T biquadratic notch filter circuit was used for compensating for the lower resonance. The filter's transfer function has zeroes which cancel the lower order complex poles of the plant's open position loop transfer function. Another pair of poles is placed on the real axis by the filter's transfer function. The circuit is shown in Figure 16, and has a transfer function as shown in the following equation:

$$
T_{N}(s)=\frac{R_{1} R_{2} C_{1} C_{2} s^{2}+R_{2}\left(C_{1}+C_{2}\right) s+1}{R_{1} R_{2} C_{1} C_{2} s^{2}+\left[R_{2}\left(C_{1}+C_{2}\right)+R_{1} C_{2}\right] s+1}
$$

If an equal capacitor design is used and resistor values are chosen such that the following relationships are true:

$$
\begin{aligned}
& R C=1 / w_{d} \\
& R_{1}=2 Q_{d} R \\
& R_{2}=\left(1 / 2 Q_{d}\right) R
\end{aligned}
$$


then the transfer function takes the following form:

$$
\begin{aligned}
T_{N}(s) & =\frac{R^{2} c^{2} s^{2}+\left(1 / Q_{d}\right) R C s+1}{R^{2} c^{2} s^{2}+\left(1 / Q_{d}+2 Q_{d}\right) R C s+1} \\
& =\frac{s^{2} / w_{d}^{2}+s /\left(Q_{d} w_{d}\right)+1}{s^{2} / w_{d}^{2}+s\left(1 / Q_{d}+2 Q_{d}\right) / w_{d}+1}
\end{aligned}
$$

Since it is desired to cancel the dominant complex pole pair in the open position loop transfer function of (14) when the compensator is cascaded with the plant, $w_{p}$ was set equal to $w_{d}$ and $Q_{p}$ was likewise set equal to $Q_{d}$, and the component values were determined. Setting $c_{1}=c_{2}=$ $\emptyset .1$ ufd, and using $\cdot w_{p}=1289 \mathrm{rad} / \mathrm{sec}$ and $Q_{p}=6.11$, the following values were determined:

$\mathrm{R}_{1}=9478 \varnothing$ ohms

$R_{2}=635$ ohms.

The resulting pole pair on the real axis is determined by factoring the denominator of the biquadratic filter's transfer function. The roots are determined to be:

$$
s_{1,2}=w_{p} *\left\{-\left(1 / 2 Q_{p}+Q_{p}\right) \pm\left[\left(1 / 2 Q_{p}+Q_{p}\right)^{2}-1\right]^{-1 / 2}\right\} .
$$

Since $w_{p}=1289 \mathrm{rad} / \mathrm{sec}(205.2 \mathrm{~Hz})$ and $Q_{p}=6.11$ the new poles are at $12.3 w_{p}$ and $\varnothing . \varnothing 813 w_{p}$ or $2524 \mathrm{~Hz}$ (15859 $\mathrm{rad} / \mathrm{sec})$ and $16.7 \mathrm{~Hz}(1 \varnothing 4.8 \mathrm{rad} / \mathrm{sec})$, respectively. This places another dominant pole very close to the free integrator's pole at the origin. The resulting notch 
filter transfer function is therefore:

$$
T_{N}(s)=\frac{s^{2} / w_{p}^{2}+s /\left(Q_{p} w_{p}\right)+1}{\left[s /\left(12 \cdot 3 w_{p}\right)+1\right]\left[s /\left(\varnothing . \varnothing 831 w_{p}\right)+1\right]}
$$

Cascading the filter with the plant will yield a root locus which has two poles that approach each other and branch away from the real axis and enter right half plane at low gain as before.

\section{Lead Compensator}

To alleviate this problem, a lead compensator is added to cancel the low frequency pole near the origin and place another much further from the origin. The lead compensator shown in Figure 17, having a tee network in the feedback path of an opamp, was used. The transfer function for the lead compensator is as follows:

$$
\begin{aligned}
\mathrm{T}_{\mathrm{L}}(\mathrm{s}) & =\frac{-2 \mathrm{R}_{4}}{\mathrm{R}_{3}}\left[\frac{\left(\mathrm{R}_{5}+\mathrm{R}_{4} / 2\right) \mathrm{C}_{3} \mathrm{~s}+1}{\mathrm{R}_{5} \mathrm{C}_{3} \mathrm{~s}+1}\right] \\
& =\mathrm{A}_{\mathrm{L}}\left[\frac{\mathrm{s} / \mathrm{w}_{\mathrm{Z}}+1}{\mathrm{~s} / \mathrm{w}_{\mathrm{D}}+1}\right]
\end{aligned}
$$

where $A_{L}$ is the $D C$ gain of the lead compensator, $w_{Z}$ and $w_{D}$ are the numerator and denominator break frequencies, respectively. These parameters are determined by the following relationships:

$$
A_{L}=\frac{-2 R_{4}}{-R_{3}}
$$




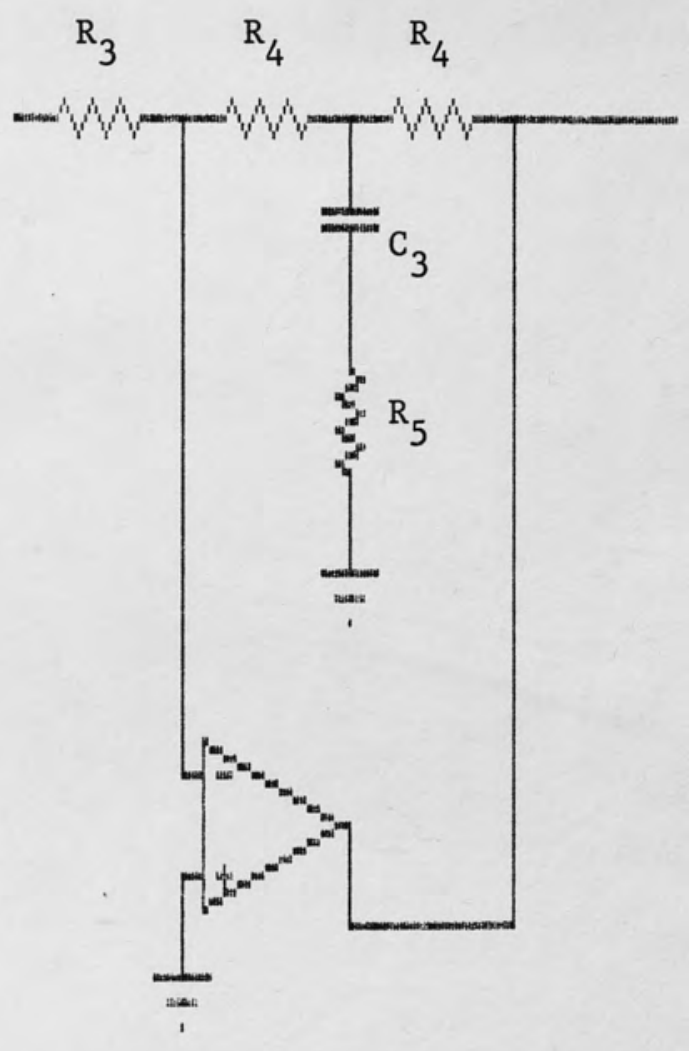

Figure 17. Lead Compensator.

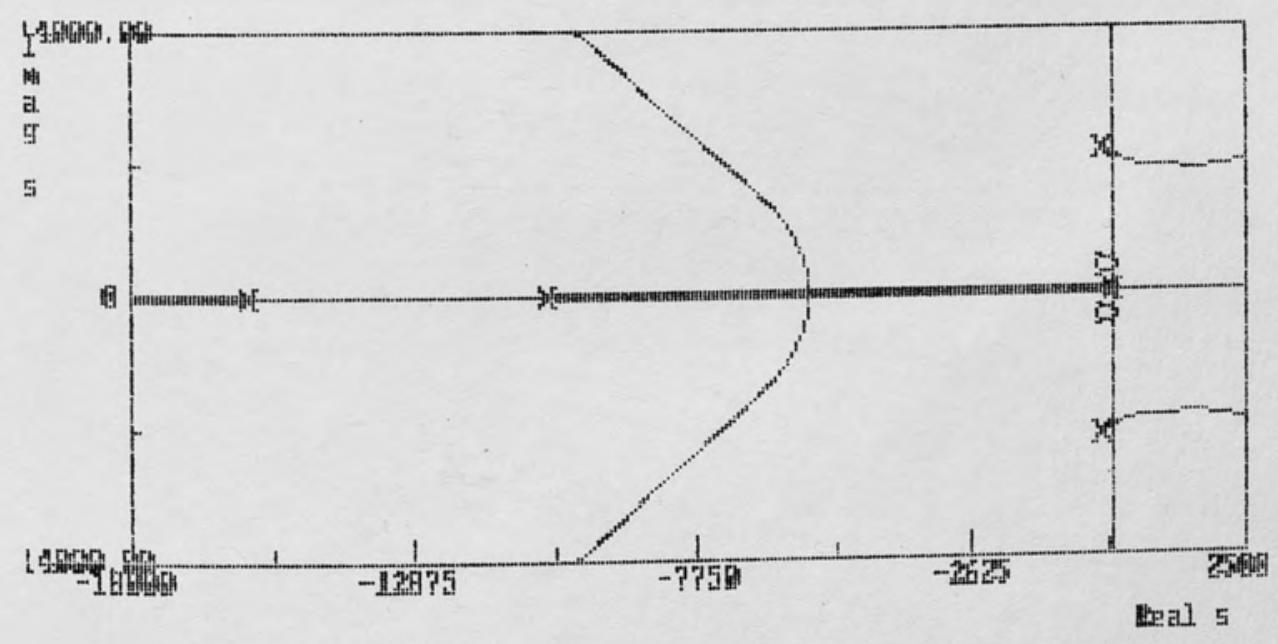

Figure 18. Root Locus of Lower Order Compensated System. 


$$
\begin{aligned}
& \mathrm{w}_{\mathrm{Z}}=\frac{1}{\left(\mathrm{R}_{5}+\mathrm{R}_{4} / 2\right) \mathrm{C}_{3}} \\
& \mathrm{w}_{\mathrm{D}}=\frac{1}{\mathrm{R}_{5} \mathrm{C}_{3}}
\end{aligned}
$$

It is desired to cancel the pole near the origin with $w_{Z}$ and place $w_{D}$ sufficiently far from the origin to allow reasonable loop gain to be introduced for combined stability and bandwidth. DC gain, $A_{L}$, is chosen to be unity and $C_{3}$ chosen to be 1 ufd. The new pole, $w_{D}$, was chosen to be $1 \varnothing \emptyset$ times $w_{z}$ for $4 \varnothing \mathrm{dB}$ gain at high frequency. With these parameters specified, the components were determined to be the following values:

$$
\begin{aligned}
& R_{3}=37814 \\
& R_{4}=18907 \\
& R_{5}=95.4 .
\end{aligned}
$$

The resulting transfer function for the lead compensator is the following:

$$
T_{L}(s)=-\frac{s /\left(\varnothing . \varnothing 831 w_{p}\right)+1}{s /\left(8.31 w_{p}\right)+1}
$$

This results in new open loop poles for the higher order model's transfer function when cascaded with the lead and notch filter compensator. The new open loop transfer function is obtained by multiplying the transfer function of the model by the transfer functions of the 
notch fílter and lead compensator, i.e.,

$$
\mathrm{T}_{\mathrm{OHC}}(\mathrm{s})=\mathrm{T}_{\mathrm{OH}}(\mathrm{s}) * \mathrm{~T}_{\mathrm{N}}(\mathrm{s}) * \mathrm{~T}_{\mathrm{L}}(\mathrm{s}) \text {. }
$$

Substituting (14), 18), and (2ø) into the above expression yields the following:

$$
\begin{aligned}
\mathrm{T}_{\mathrm{OHC}}(\mathrm{s}) & =\frac{\mathrm{Vo}_{\mathrm{A}}}{\mathrm{V}_{\mathrm{r}}} \\
= & \frac{-1}{\mathrm{R}_{\text {in }} \mathrm{C}_{\mathrm{T}} \mathrm{s}\left[\mathrm{s} / \mathrm{w}_{1}+1\right]\left[\mathrm{s} / \mathrm{w}_{2}+1\right]\left(\mathrm{s}^{2} / \mathrm{w}_{\mathrm{H}}^{2}+\mathrm{s} /\left(\mathrm{Q}_{\mathrm{H}} \mathrm{w}_{\mathrm{H}}\right)+1\right)}
\end{aligned}
$$

where $\mathrm{T}_{\mathrm{OHC}}(\mathrm{s})$ is the higher order model's compensated open position loop transfer function. The new poles on the real axis are $w_{1}$ and $w_{2}$, and are at $8.13 w_{p}(1668 \mathrm{~Hz}, 10482$ $\mathrm{rad} / \mathrm{sec})$ and $12.3 \mathrm{w}_{\mathrm{p}}(2524 \mathrm{~Hz}, 15859 \mathrm{rad} / \mathrm{sec})$, respectively.

The resulting root locus is shown in Figure 18. The higher order complex poles now enter the right half plane at an overall adjustable loop gain of $850 \mathrm{sec}^{-1}$. To ensure stability in the event that the higher order pole resonant frequency is excited, compensation similar to that used for the lower order complex pole pair is used for the higher order pole pair.

\section{Higher order Compensation}

Using the same design procedure as with the lower order complex pole pair with a frequency, $\mathrm{w}_{\mathrm{H}}=6849 \mathrm{rad} / \mathrm{sec}$ 
$(1 \varnothing 9 \varnothing \mathrm{Hz})$, and quality factor, $Q_{\mathrm{H}}=14$, the resulting biquadratic notch filter transfer function is the following:

$$
\mathrm{T}_{\mathrm{NH}}(\mathrm{s})=\frac{\mathrm{s}^{2} / \mathrm{w}_{\mathrm{H}}^{2}+\mathrm{s} /\left(\mathrm{Q}_{\mathrm{H}} \mathrm{w}_{\mathrm{H}}\right)+1}{\left[\mathrm{~s} /\left(28 \mathrm{w}_{\mathrm{H}}\right)+1\right]\left[\mathrm{s} /\left(\varnothing . \varnothing 357 \mathrm{w}_{\mathrm{H}}\right)+1\right]}
$$

The necessary lead compensation transfer function for eliminating the pole at $\varnothing . \varnothing 357 \mathrm{w}_{\mathrm{H}}(38.9 \mathrm{~Hz}, 244 \mathrm{rad} / \mathrm{sec})$ is the following expression:

$$
\mathrm{T}_{\mathrm{LH}}(\mathrm{s})=-\left[\frac{\mathrm{s} /\left(\varnothing . \varnothing 357 \mathrm{w}_{\mathrm{H}}\right)+1}{\mathrm{~s} /\left(3.57 \mathrm{w}_{\mathrm{H}}\right)+1}\right.
$$

When the higher order compensator is cascaded with the lower order compensated model, the resulting transfer function is as follows:

$$
\begin{aligned}
\mathrm{T}_{\mathrm{OF}}(\mathrm{s})= & \frac{\mathrm{Vo}_{\mathrm{A}}}{\mathrm{V}_{\mathrm{r}}} \\
= & \frac{-1}{\mathrm{R}_{\text {in }} \mathrm{C}_{\mathrm{T}} \mathrm{s}\left[\mathrm{s} / \mathrm{w}_{1}+1\right]\left[\mathrm{s} / \mathrm{w}_{2}+1\right]\left[\mathrm{s} / \mathrm{w}_{3}+1\right]\left[\mathrm{s} / \mathrm{w}_{4}+1\right]}
\end{aligned}
$$

where $\mathrm{T}_{\mathrm{OF}}(\mathrm{s})$ is the higher order model's fully compensated open position loop transfer function. The pole frequencies, $w_{1}$ and $w_{2}$, are as defined in (21). The pole frequencies, $w_{3}$ and $w_{4}$, are $3.57 w_{\mathrm{H}}(3891 \mathrm{~Hz}, 2445 \emptyset$ $\mathrm{rad} / \mathrm{sec})$ and $28 \mathrm{w}_{\mathrm{H}}(3 \varnothing 52 \varnothing \mathrm{Hz}, 191763 \mathrm{rad} / \mathrm{sec})$, respectively. 


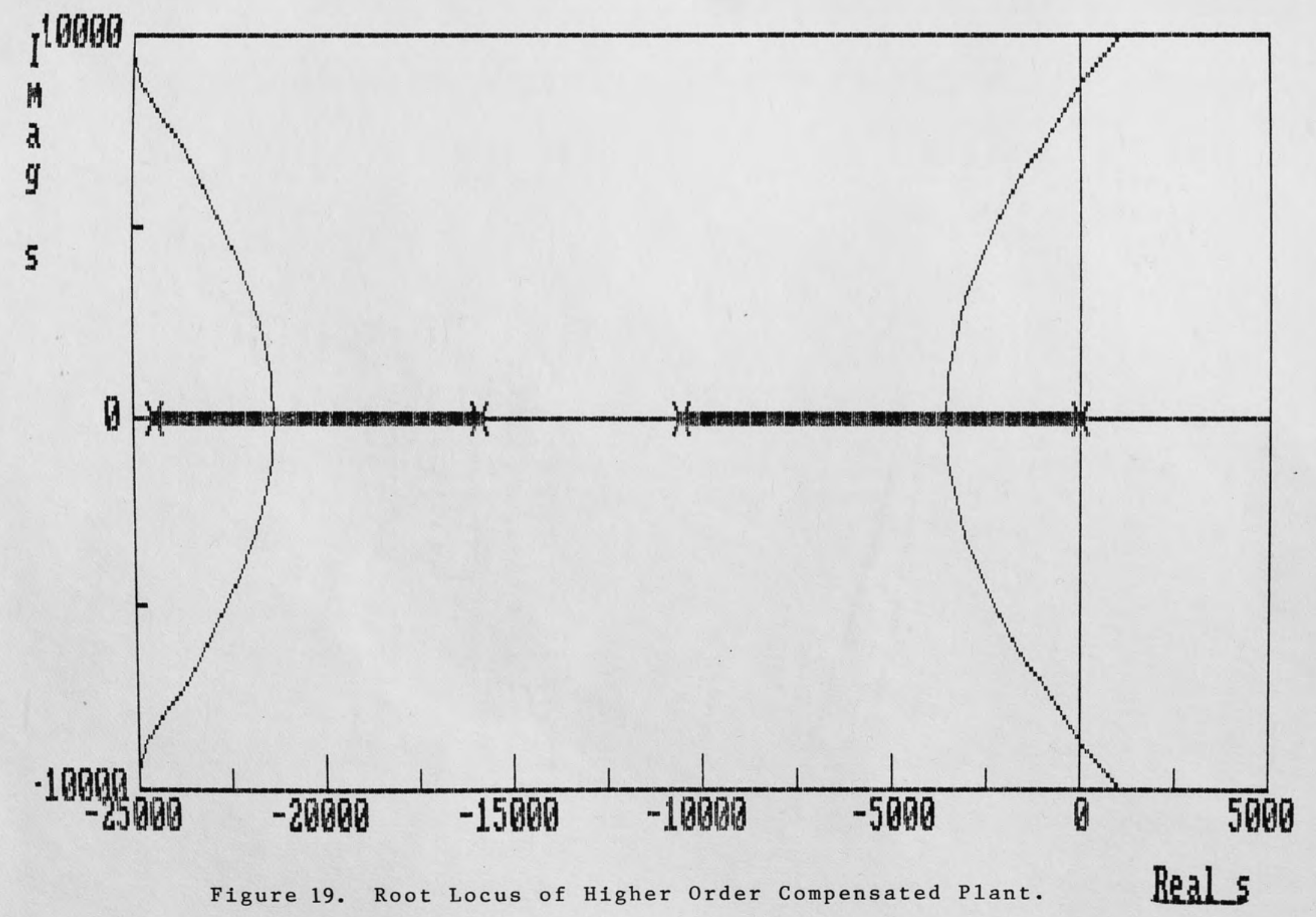


The root locus of the compensated system is shown in Figure 19. The scaling of the plot was chosen for clarity of the dominant poles and therefore does not show the locus of the pole at $28 \mathrm{w}_{\mathrm{H}}$. Its trajectory with increased gain is simply to the left along the real axis. The polezero cancellations due to the notch filters are left off the plot for clarity also.

The component values to be used in the higher order biquadratic notch filter (using the same subscript notation) are as follows:

$$
\begin{aligned}
& \mathrm{c}_{1}=\mathrm{c}_{2}=\mathrm{c}=\emptyset . \emptyset 1 \text { ufd } \\
& \mathrm{R}_{1}=4 \emptyset 88 \emptyset \emptyset \text { ohms } \\
& \mathrm{R}_{2}=52 \emptyset \text { ohms. }
\end{aligned}
$$

The component values to be used in the higher order lead compensator (again using the same subscript notation) are as follows:

$$
\begin{aligned}
& C_{3}=c=1 \text { ufd } \\
& R_{3}=16196 \text { ohms } \\
& R_{4}=8 \varnothing 98 \text { ohms } \\
& R_{5}=4 \varnothing .9 \text { ohms. }
\end{aligned}
$$

The following chapter analyzes the closed loop system with the compensated plant and designs for desired system performance. 


\section{COMPENSATED SYSTEM ANALYSIS AND DESIGN}

Now that compensation has been introduced into the control loop, the loop is closed utilizing the output of a position sensor, and the overall transfer function is determined as was done for the uncompensated system. Next, component values are determined for desired system performance.

\section{System Analysis}

A convenient point for introducing the feedback signal is at the summing junction of the first lead compensator in the cascaded system. This is shown in Figure $2 \varnothing$ where the reference and feedback signals are summed through the resistors $R_{r}$ and $R_{f}$, respectively.

Also introduced into the forward path is a noninverting amplifier which doubles as a buffer and an amplifier to insert loop gain for system response. This is shown in Figure $2 \varnothing$ just prior to the plant input resistance. The gain of the stage is determined by the following relationship:

$$
A_{N}=1+\frac{R_{6}}{R_{7}} .
$$

To determine the system transfer function, we start with the following relationship: 


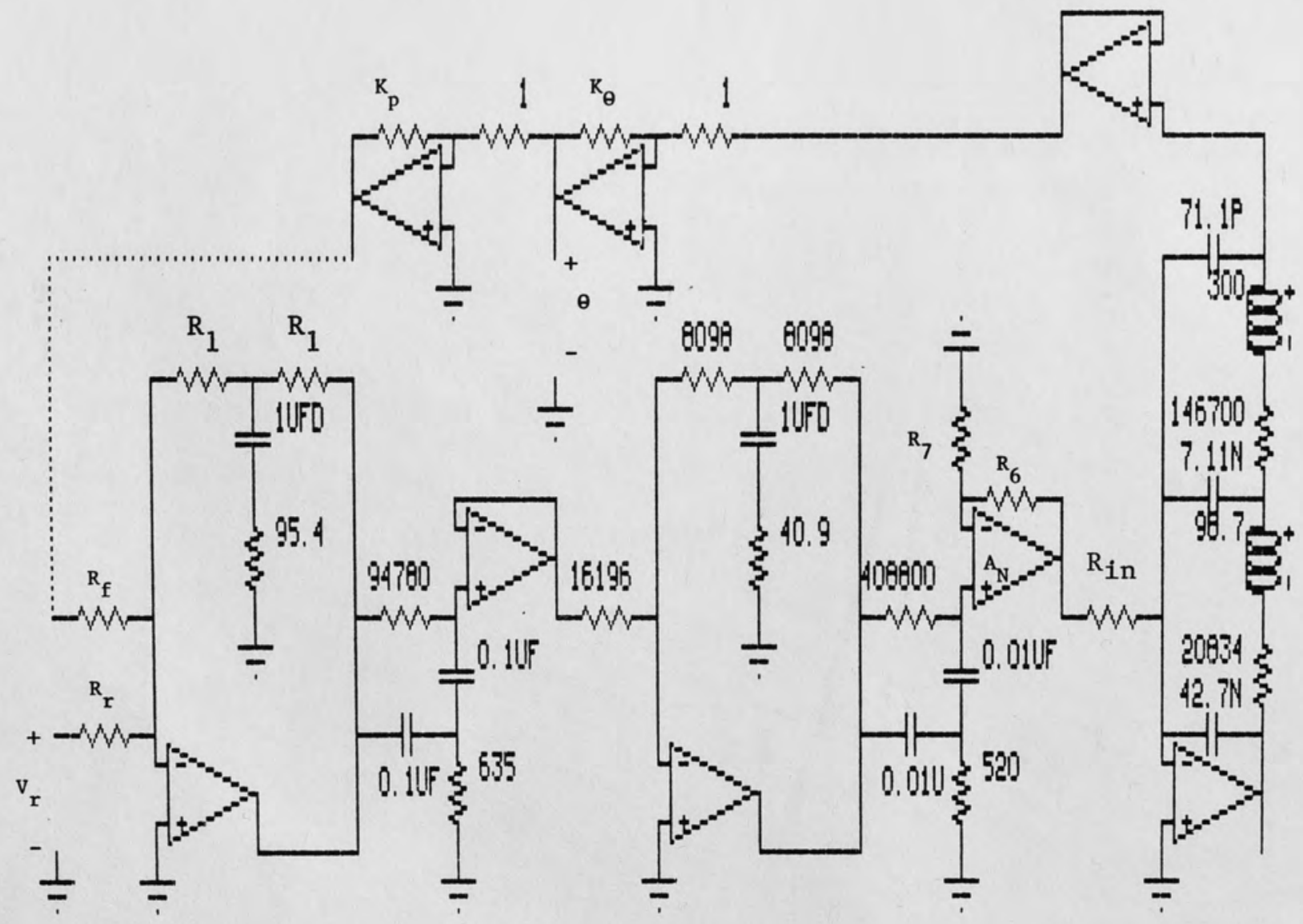

Figure 20. Closed Loop System Mode1. 


$$
\left.v_{p}=-\underset{R_{f}}{2 R_{1}} * \frac{v_{p}}{R_{r}}+\frac{v_{r}}{-\underline{n}}\right] * A_{N} * T_{O F}(s) * K_{\Theta} * K_{p}
$$

where

$$
\mathrm{V}_{\mathrm{p}}=\theta^{\star} \mathrm{K}_{\mathrm{p}}
$$

and $\mathrm{T}_{\mathrm{OF}}(\mathrm{s})$ is the fully compensated open position loop transfer function of the the actuator model. Substituting (24) and (26) into (25) yields the following relationship:

$$
\frac{\Theta}{v_{r}}=\frac{-\left[\left(2 R_{1} A_{N}\right) / R_{r}\right]^{*} K_{\Theta}}{R_{i n} C_{T} s\left[s / w_{1}+1\right]\left[s / w_{2}+1\right]\left[s / w_{3}+1\right]\left[s / w_{4}+1\right]+K}
$$

where

$$
K=\frac{2 R_{1} A_{N} K_{\Theta} K_{p}}{R_{f}}
$$

This leads to the following block diagram:

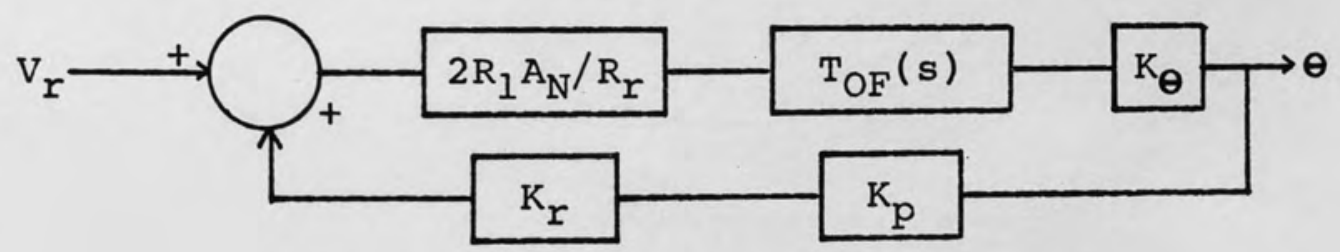

where the resistor ratio,

$$
\mathrm{K}_{\mathrm{r}}=\mathrm{R}_{\mathrm{r}} / \mathrm{R}_{\mathrm{f}} \text {. }
$$

An alternative way to show the overall system transfer function is to divide numerator and denominator by $R_{\text {in }} C_{T}$ yielding the following equation:

$$
\frac{\Theta}{v_{r}}=\frac{-K_{v} K_{\theta}}{s\left[s / w_{1}+1\right]\left[s / w_{2}+1\right]\left[s / w_{3}+1\right]\left[s / w_{4}+1\right]+K^{\prime}}
$$

where 


$$
K_{v}=\frac{2 R_{1} A_{N}}{R_{r} R_{i n} C_{T}},
$$

and

$$
K^{\prime}=\frac{2 \mathrm{R}_{1} \mathrm{~A}_{N} K_{\theta} K_{p}}{R_{f} R_{\text {in }} C_{T}} .
$$

$K_{V}$ is the ramp error coefficient and $K^{\prime}$ is the overall adjustable loop gain. Now that the closed loop transfer function is derived, parameter values can be determined to obtain desired system performance.

\section{System Design}

In this section the DC gain, closed loop pole locations, and steady state error criteria are related to the system parameters. The parameters are then selected to achieve reasonable system performance. (The desired system performance, as yet to be stated, will solely be determined by the closed loop pole locations).

The overall DC gain, $A_{D C}$, is determined by setting $s=$ $\emptyset$ in the overall transfer function. This is shown in the following equation:

$$
\mathrm{K}_{\mathrm{DC}}=\frac{\mathrm{R}_{\mathrm{f}}}{\mathrm{R}_{\mathrm{r}} \mathrm{K}_{\mathrm{p}}} .
$$

It is generally desirable to have the feedback signal on the same order of magnitude as the reference signal in order to minimize the effects of noise. It is also desired to make the lead compensator have unity gain at DC. To satisfy both these requirements, make $R_{r}=R_{f}=2 R_{1}$. This 
results in a ramp error coefficient, DC gain and overall adjustable loop gain as determined in the following equations :

$$
\begin{aligned}
& \mathrm{K}_{\mathrm{v}}= \frac{\mathrm{A}_{\mathrm{N}}}{\mathrm{R}_{\text {in }} \mathrm{C}_{\mathrm{T}}}, \\
& \mathrm{K}_{\mathrm{DC}}=\frac{1}{\mathrm{~K}_{\mathrm{p}}},
\end{aligned}
$$

and

$$
K^{\prime}=\frac{{ }_{N^{-} K_{\Theta} K_{p}}^{\mathrm{A}_{\text {in }} C_{T}}}{R}
$$

Note that the ramp error coefficient $K_{v}$, and the overall adjustable loop gain $\mathrm{K}^{\prime}$, are determined by the ratio of the non-inverting amplifier gain $\mathrm{A}_{\mathrm{N}}$, and the product $\mathrm{R}_{\mathrm{in}} \mathrm{C}_{\mathrm{T}}$, where $\mathrm{C}_{\mathrm{T}}$ cannot be adjusted. The product of the position sensor gain, $K_{p}$, and electromechanical scale factor, $K_{\theta^{\prime}}$ is $1 \varnothing .8 \mathrm{mV} / \mathrm{V}$ and the value of $C_{T}$ is $49.8 \mathrm{nfd}$.

By observing (29) and (31) it is noticed that the parameters $K_{V}$ and $K^{\prime}$ can be independently set since the ramp error coefficient, $K_{v}$, does not depend on the position sensor gain, $K_{p}$. However, $K_{p}$ will be considered a fixed parameter to make $K^{\prime}$ and $K_{V}$ dependent on each other. It is not specifically desired to set the ramp error coefficient for determining steady state error to a ramp input. The main concern at this point is system stability. 
Pole Placement

Figure 21 shows that a value of $\mathrm{K}^{\prime}$ equal to $23 \emptyset \emptyset \mathrm{sec}^{-1}$ will give a pair of dominant poles with a damping ratio of $\emptyset .73$ and a damped natural frequency of $463 \mathrm{~Hz}$. Placing the poles here will give generally good tradeoff between bandwidth and stability. To place the dominant poles at these locations in the complex plane, the following relationship is determined from (31) and the value of $\mathrm{K}^{\prime}=$ $23 ø \varnothing \sec ^{-1}$ :

$$
R_{\text {in }}=94 \cdot 3 A_{N} \text {. }
$$

This shows the necessary relationship between the plant input resistance and the non-inverting amplifier gain for these pole locations.

Since the non-inverting amplifier "drives" the plant through the plant input resistance $R_{i n}$, the amplifier gain should be made reasonably high so that amplifier output impedance is at least an order of magnitude smaller $($ < $\emptyset .1$ times) than the plant input resistance. A reasonable choice for $A_{N}$ is $1 \varnothing(2 \varnothing \mathrm{dB})$, making the necessary value for $R_{\text {in }}$ be 943 ohms for proper pole placement. With the poles at the desired locations, the ramp error coefficient is set at the following value:

$$
\mathrm{K}_{\mathrm{v}}=2.13 \times 1 \emptyset^{5} \mathrm{sec}^{-1} \text {. }
$$

The DC gain is found to be the following:

$$
\mathrm{K}_{\mathrm{DC}}=\varnothing . \varnothing 4 \mathrm{rad} / \mathrm{volt} \text {. }
$$




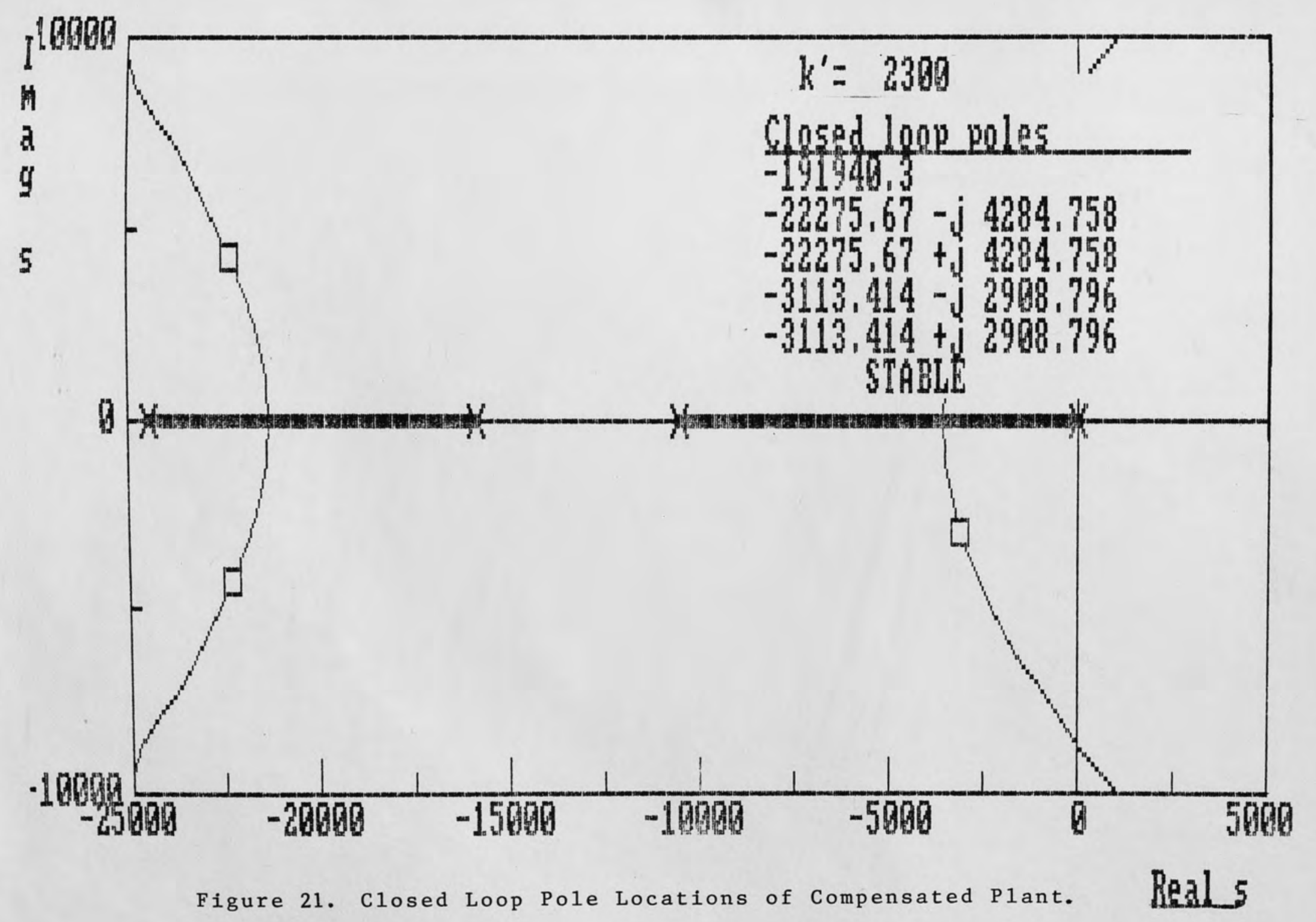


All'the parameter values that give desired system response are now known. These are given below:

$$
\begin{aligned}
& \mathrm{K}^{\prime}=23 \emptyset \emptyset \mathrm{sec}^{-1} \\
& \mathrm{~A}_{\mathrm{N}}=1 \emptyset \mathrm{volts} / \mathrm{volt} \\
& \mathrm{R}_{\text {in }}=943 \mathrm{ohms} \\
& \mathrm{K}_{\mathrm{V}}=2.13 \times 1 \emptyset^{5} \mathrm{sec}^{-1} \\
& \mathrm{~K}_{\mathrm{DC}}=\emptyset . \emptyset 4 \mathrm{rad} / \mathrm{volt} .
\end{aligned}
$$

The circuit is shown in Figure 22 with all component values. The product of $\mathrm{K}_{\boldsymbol{\theta}}$ and $\mathrm{K}_{\mathrm{p}}$ is modeled as a voltage divider network to yield a gain of $10.8 \mathrm{mv} / \mathrm{v}$.

The uncompensated plant open loop frequency response is obtained using a software package called MICROCAP II and is illustrated in Figure 23. Figure 24 shows the compensated plant's open loop frequency response and gives a phase margin of approximately $6 \emptyset$ degrees and a gain margin of approximately $13 \mathrm{~dB}$. (The simulation adds an additional 180 degrees phase shift; therefore instability occurs if gain is greater than $\emptyset \mathrm{dB}$ when phase is $-36 \varnothing$ degrees).

The closed loop frequency response is shown in Figure 25. The resulting bandwidth is approximately $65 \varnothing \mathrm{Hz}$. This is about $350 \mathrm{~Hz}$ more bandwidth than Tomasetti's prototype with an added feature of zero steady state error to a step input. Actual system response is discussed in Chapter 8. 


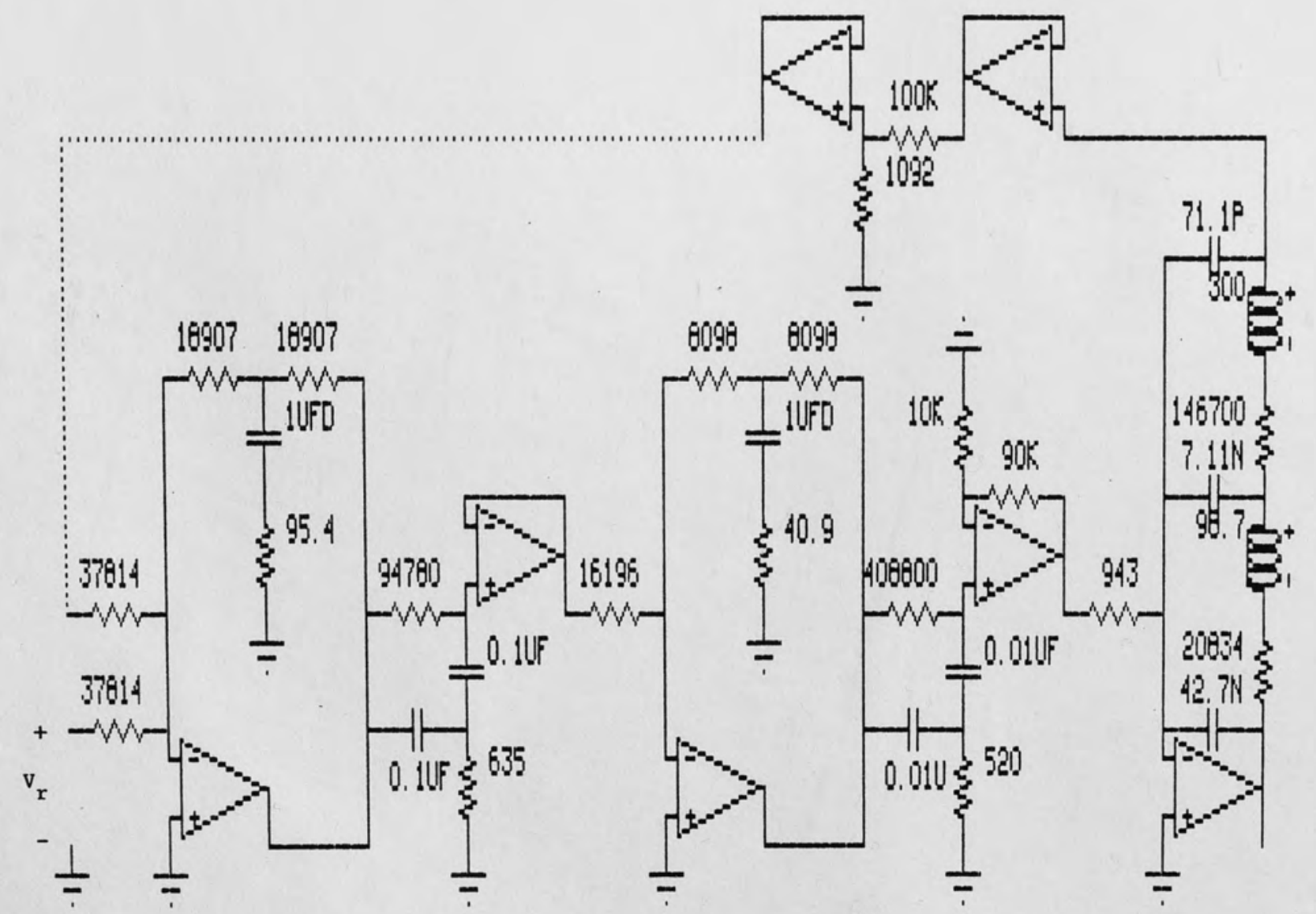

Figure 22. Closed Loop System Circuit. 


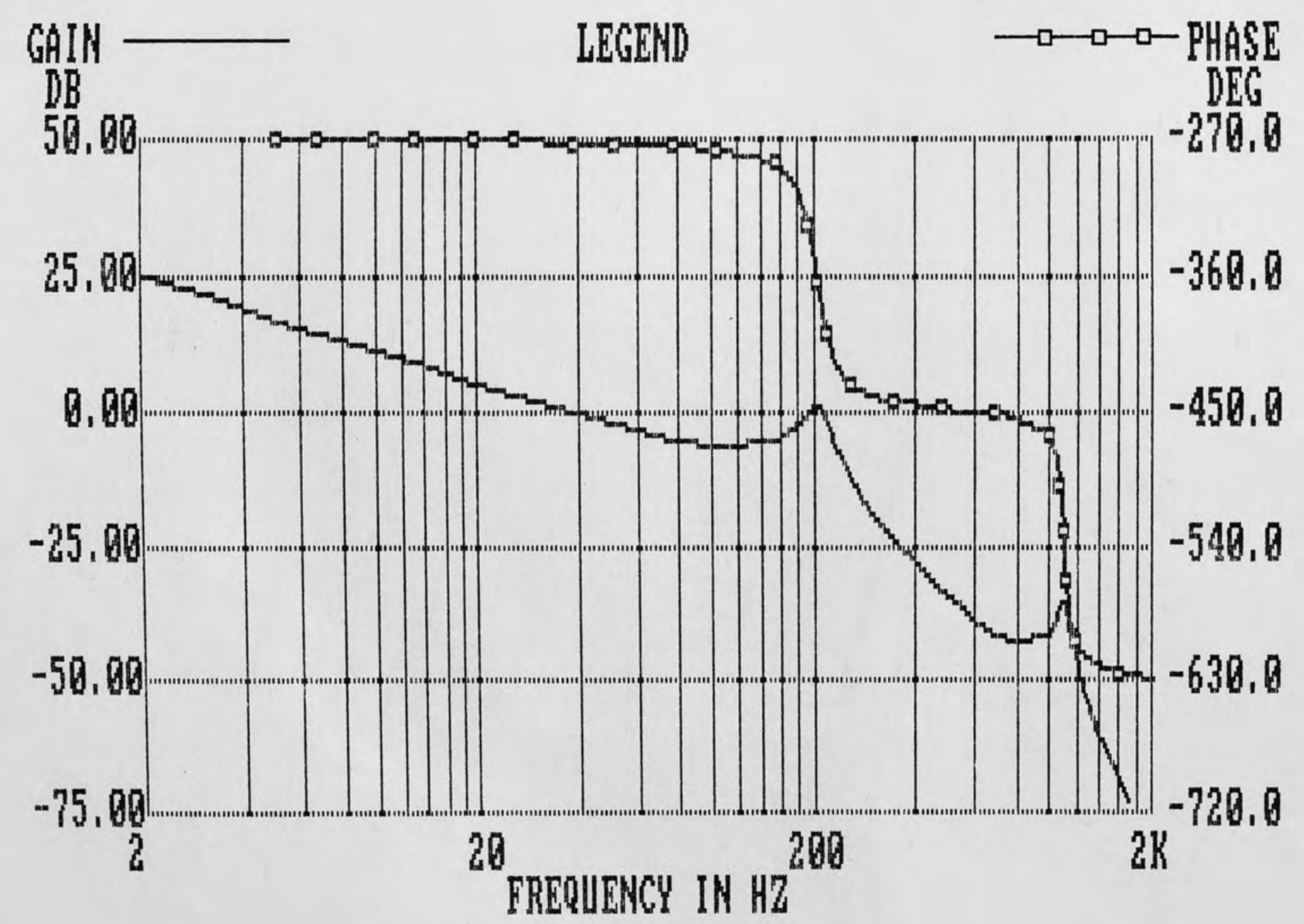

Figure 23. Uncompensated P1ant Open Loop Response. 


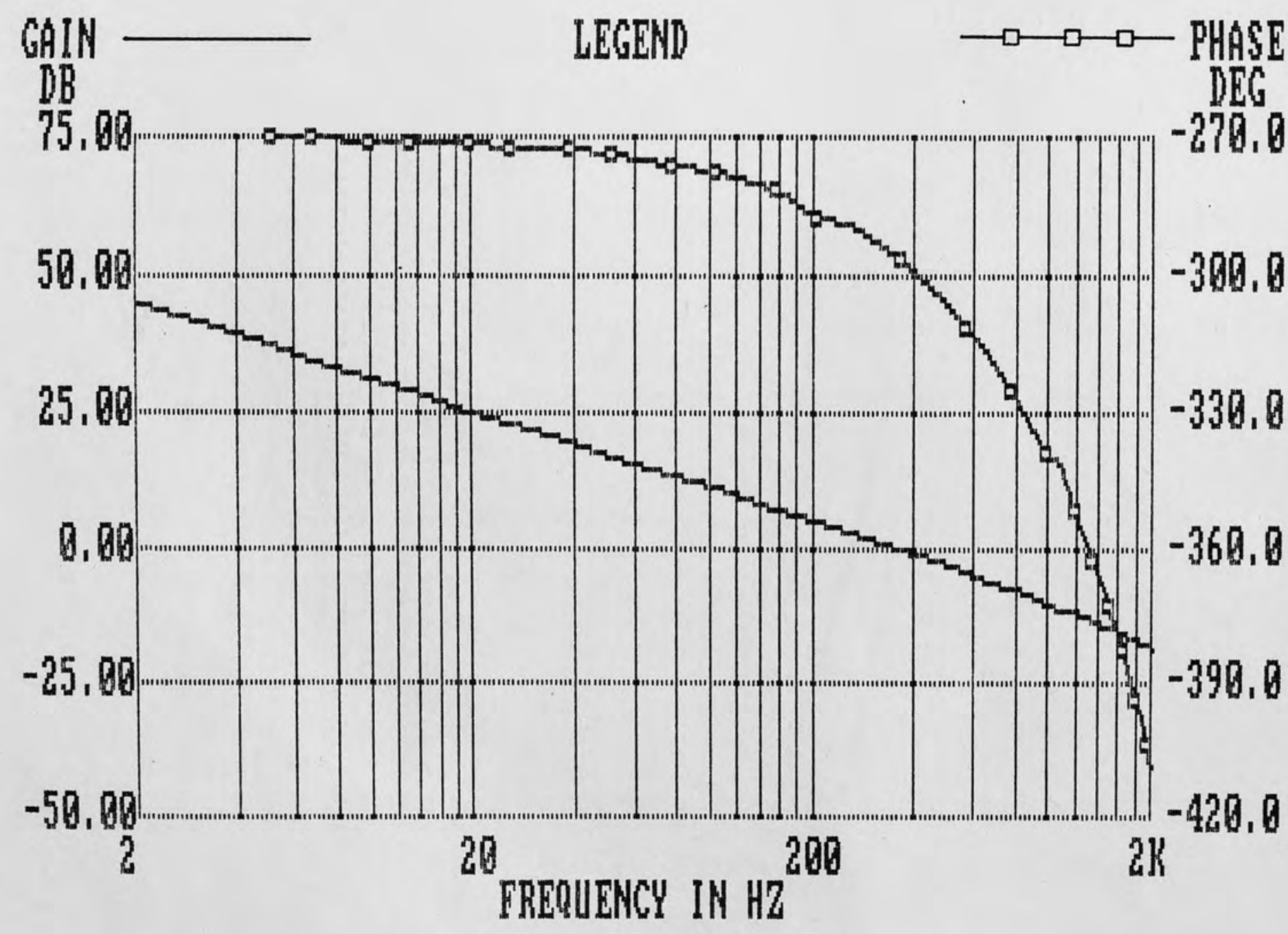

Figure 24. Compensated P1ant Open Loop Response. 


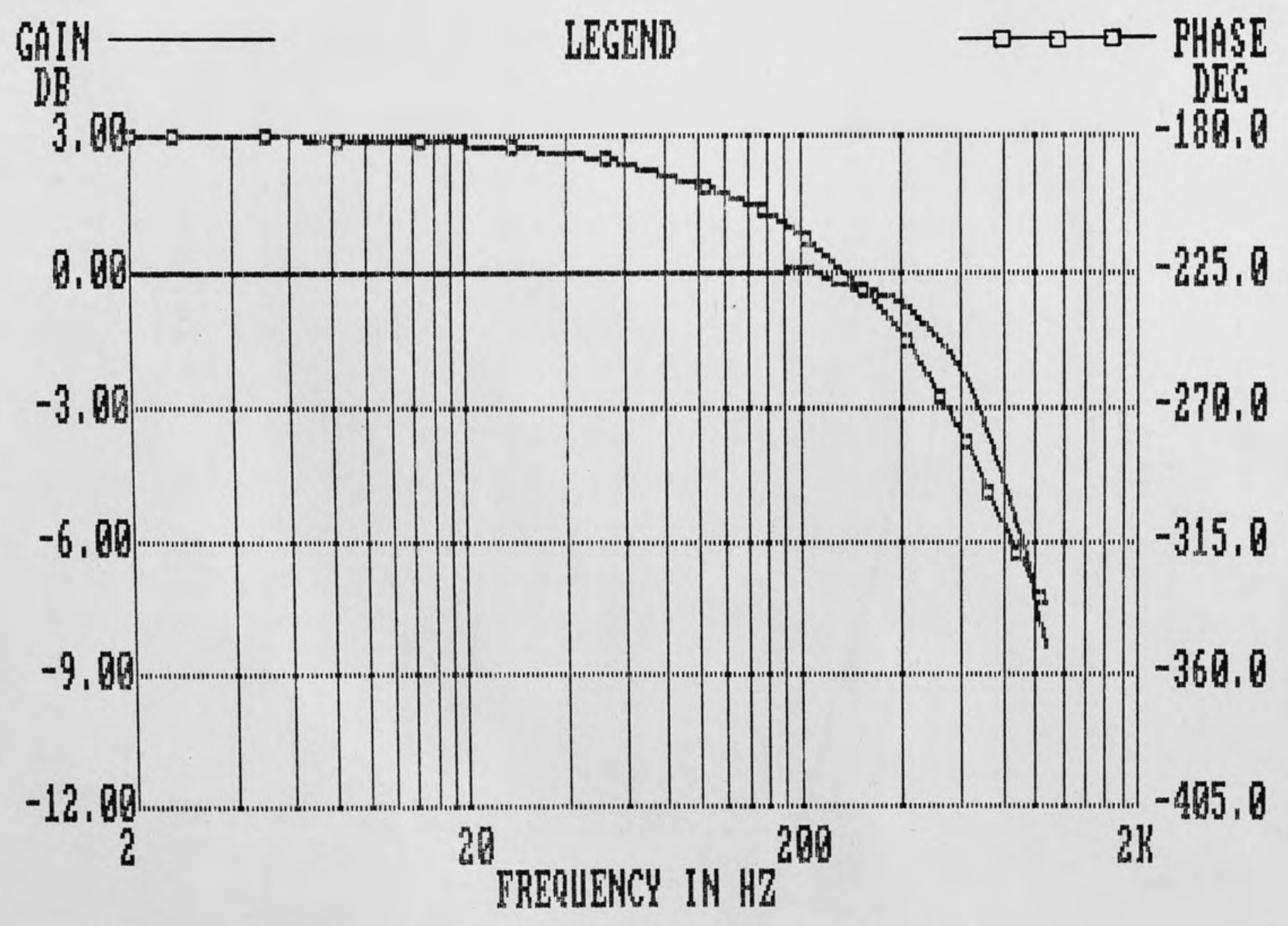

Figure 25. Compensated Plant Closed Loop Response. 


\section{POSITION SENSOR}

In order to send a reliable position feedback signal to the summing junction of the first compensator's opamp, a position detector with good resolution is required. It is desired to measure the position without any mechanical linkages to the actuator or mirror. Such linkage would affect the dynamic response in a detrimental way, robbing potential bandwidth from the system, i.e., adding effective mass to the actuator mechanism.

The method utilized in this thesis is the same as the one used in [1] (with slight modification). A proximity detector senses the distance that two of the mirror edges are from two stationary inductive coils mounted on opposite sides of the mirror's pivot axis. Each coil is in near proximity to its respective edge. The sensor relies on the Eddy current phenomenon and was chosen for its simplicity and sensitivity.

A brief description of the overall operation and the modifications is given below. Further details are given in [1].

Shown in Figure 2 is the location of the inductive coil pickups with respect to the mirror edges. These coils are the inductors in two separate colpitts oscillators. When a mirror edge is close to its respective coil, the 
associated oscillator output amplitude decreases. Due to the symmetry of operation, when one edge approaches its respective coil, the opposite edge moves away from its coil. The output of each oscillator is then rectified and filtered and sent to a difference amplifier. The output of the difference amplifier is therefore the positional voltage and is proportional to the angle of deflection.

A schematic of the position detector is shown in Figure 26. The first modification was the addition of a current limiting PNP transistor. The added transistor served to prevent a "slow" steady heat up of the FET in the oscillator, thereby preventing a slow temperature drift which tended to cause slow position drift in steady state.

This temperature drift resulted in the oscillator's amplitude changing with time at differing rates causing the position signal to drift with no mirror motion. With the loop closed, this would result in mirror movement without a changing reference signal. The PNP dissipated most of the heat, keeping the FET relatively close to ambient temperatures. Heat sinks were attached to the PNP transistors in order to prevent similar drift due their temperature change (primarily due to rapid transient temperature variations).

The second modification was the placement of the oscillators physically close to the actuator in order to minimize the length of the inductive coil leads to the 


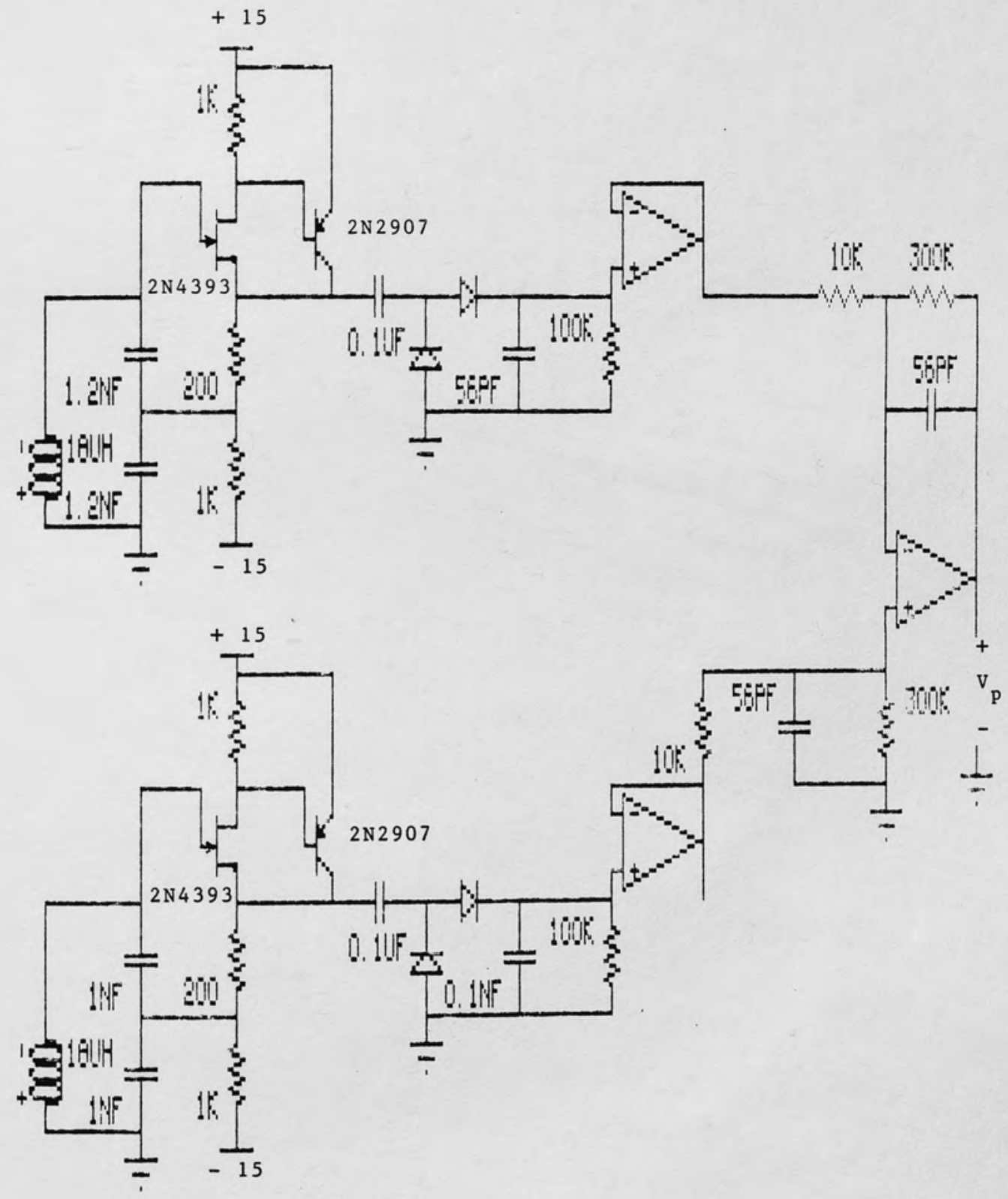

Figure 26. Position Sensor Schematic. 
circuit board. This served to minimize the "RF' crosstalk" between the two oscillators, thereby minimizing the noise introduced into the feedback signal. 


\section{RESULTS}

Before testing the completed system, each subsystem was tested and analyzed. This simplified troubleshooting when the results were not as expected.

Figures 27 and 28 show the predicted response of the lower order and higher order lead compensators, respectively, using MICROCAP II. Figures 29 and $3 \varnothing$ show the photographs of the tested compensators using a spectrum analyzer. Note that Figures 27 and 28 have logarithmic horizontal scales while Figures 29 and $3 \varnothing$ have linear horizontal scales. These figures compare favorably.

Figures 31 and 32 show the predicted response of the lower order biquadratic notch filters. Figures 33 and 34 show the photographs of the tested notch filters using the spectrum analyzer. Again, the figures compare favorably.

The actual closed loop performance is compared to the predicted response in Figure 35 . The bandwidth was not as high as anticipated and conclusions as to why are addressed in the next chapter.

The resolution of the actuator was determined by deenergizing the control circuitry and measuring the width of the reflected laser beam off a distant wall (2ø4 inches away). The circuit was reenergized, with a zero reference voltage applied, and the width of the beam was remeasured 
between extreme ends of its travel. The difference between the two measurements is the resolution to which the beam could be targeted. This resulted in $\varnothing .918$ milliradians (Ø.Ø53 degrees) resolution.

The linearity was observed by applying DC reference voltages to the system input and measuring the deflection for each applied voltage. The linearity can be demonstrated by the following observed measurements.

$\frac{\text { Applied Reference Voltage }}{\text { (Volts) }}$

$$
\begin{aligned}
& 1.42 \\
& 2.84 \\
& 4.26
\end{aligned}
$$

$\frac{\text { Measured Deflection }}{\text { (Inches Arc Length) }}$

$1.4\left(0.39^{\circ}\right)$
$2.8\left(0.79^{\circ}\right)$
$4.3\left(1.21^{\circ}\right)$

Figure 36 shows the response to a step input. The response is monitored by the position sensor's output voltage. The output tracks the input (after the transients die) without any detectable error, thereby showing the zero steady state error to a step input. The gain was adjusted to give a $2 \varnothing$ percent overshoot. The resulting gain margin is $7.5 \mathrm{~dB}$. The difference between the predicted gain margin and that actually achieved is discussed in the next chapter. 


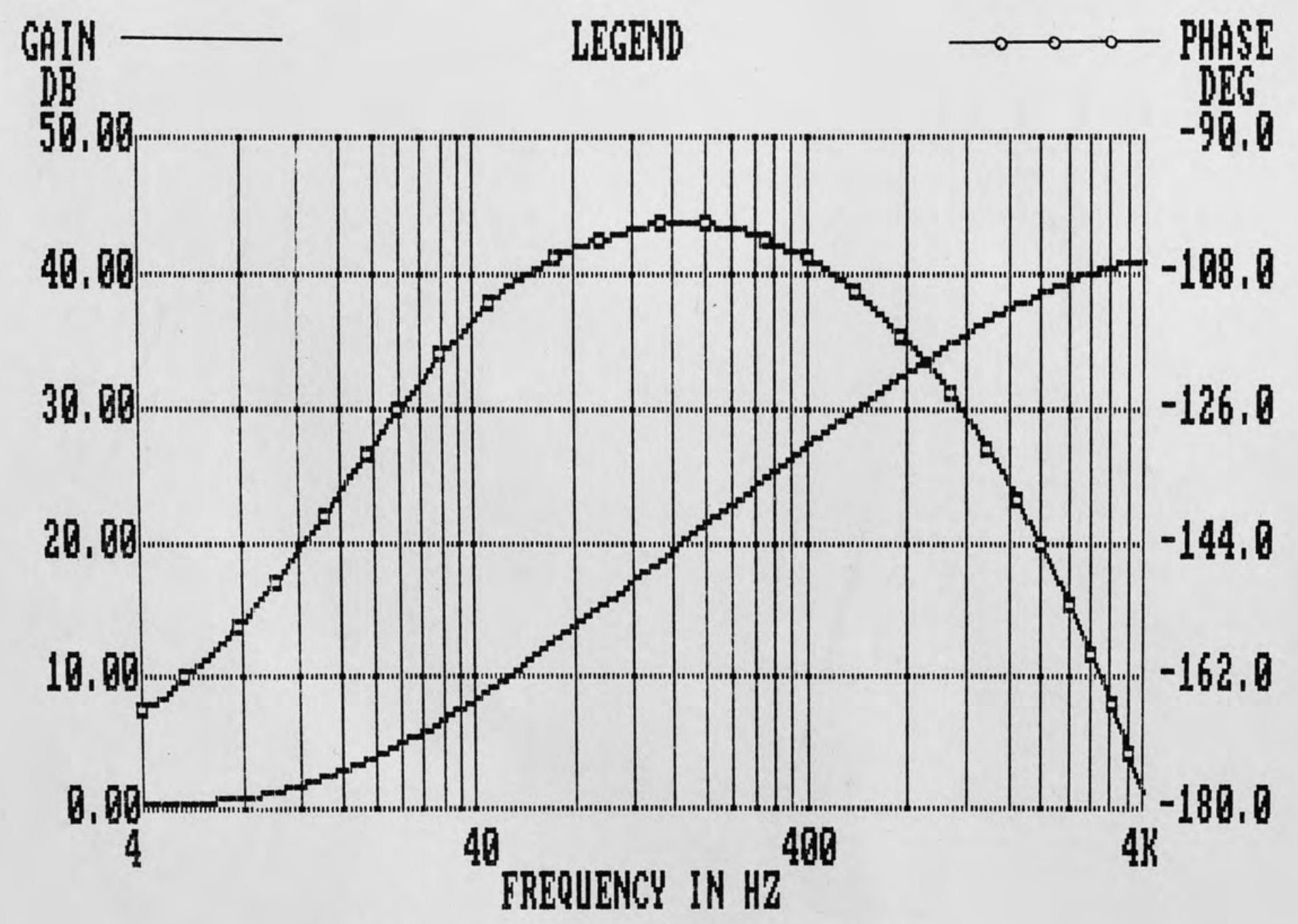

Figure 27. Lower Order Lead Response. 


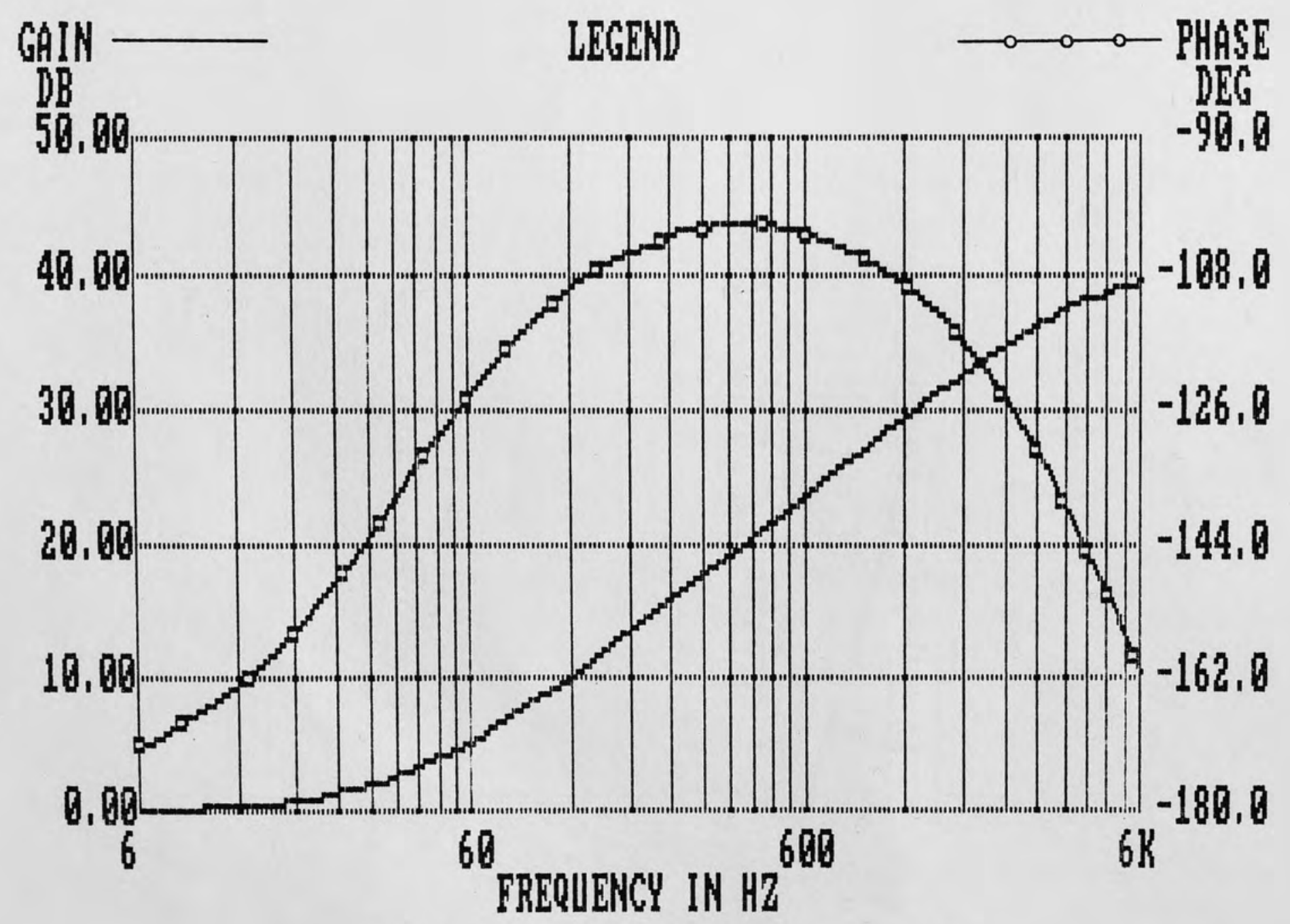

Figure 28. Higher Order Lead Response. 


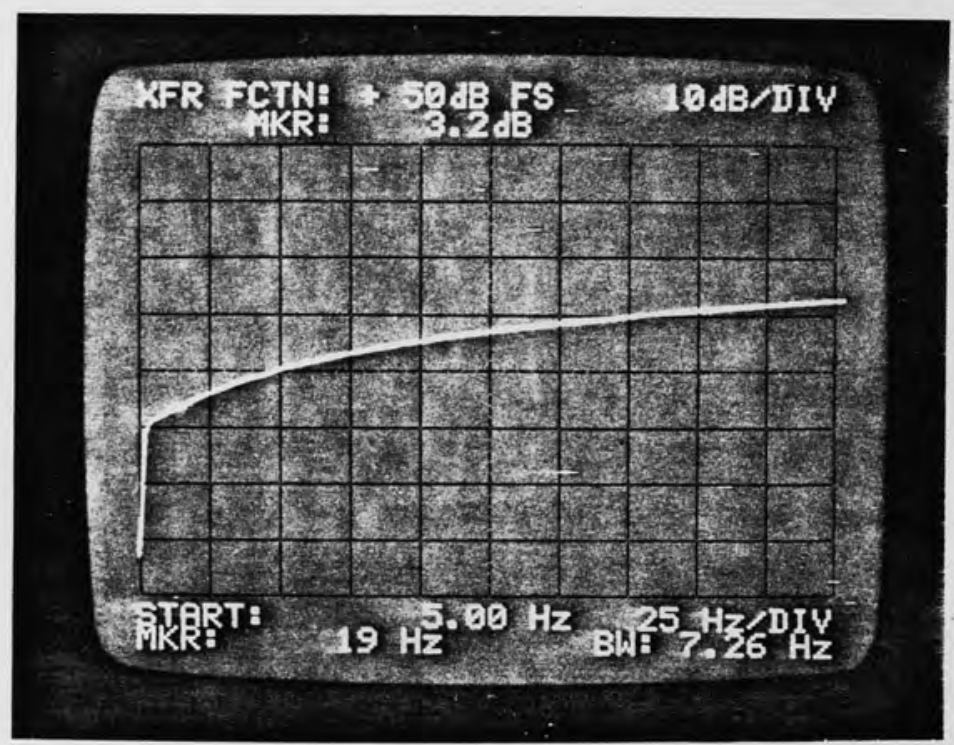

Figure 29. Lower Order Lead Photographed Response.

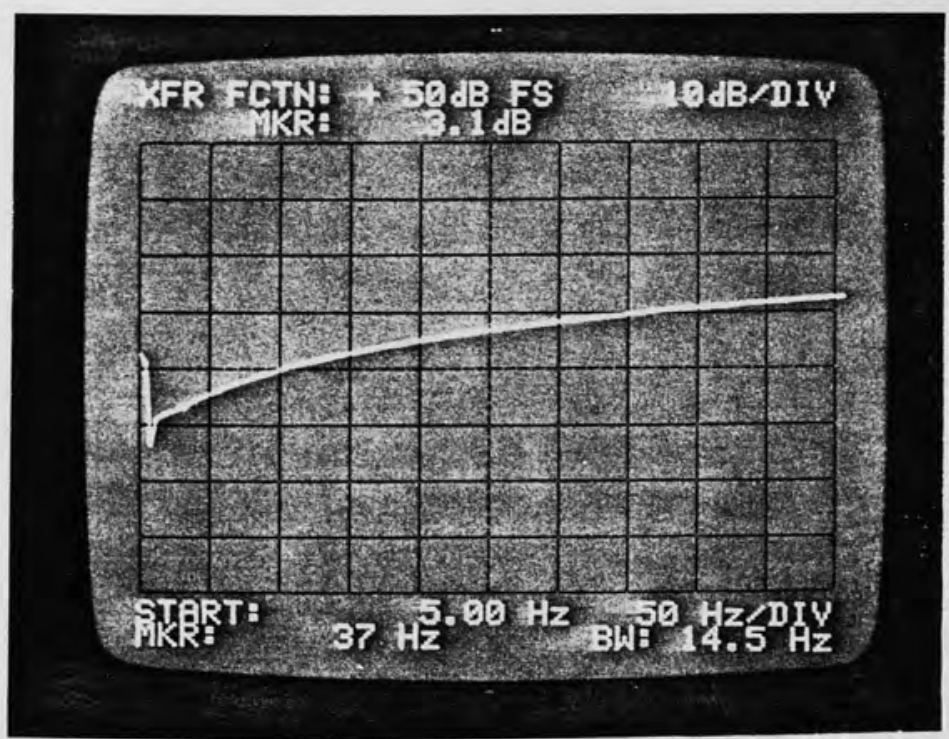

Figure 3ø. Higher order Lead Photographed Response. 


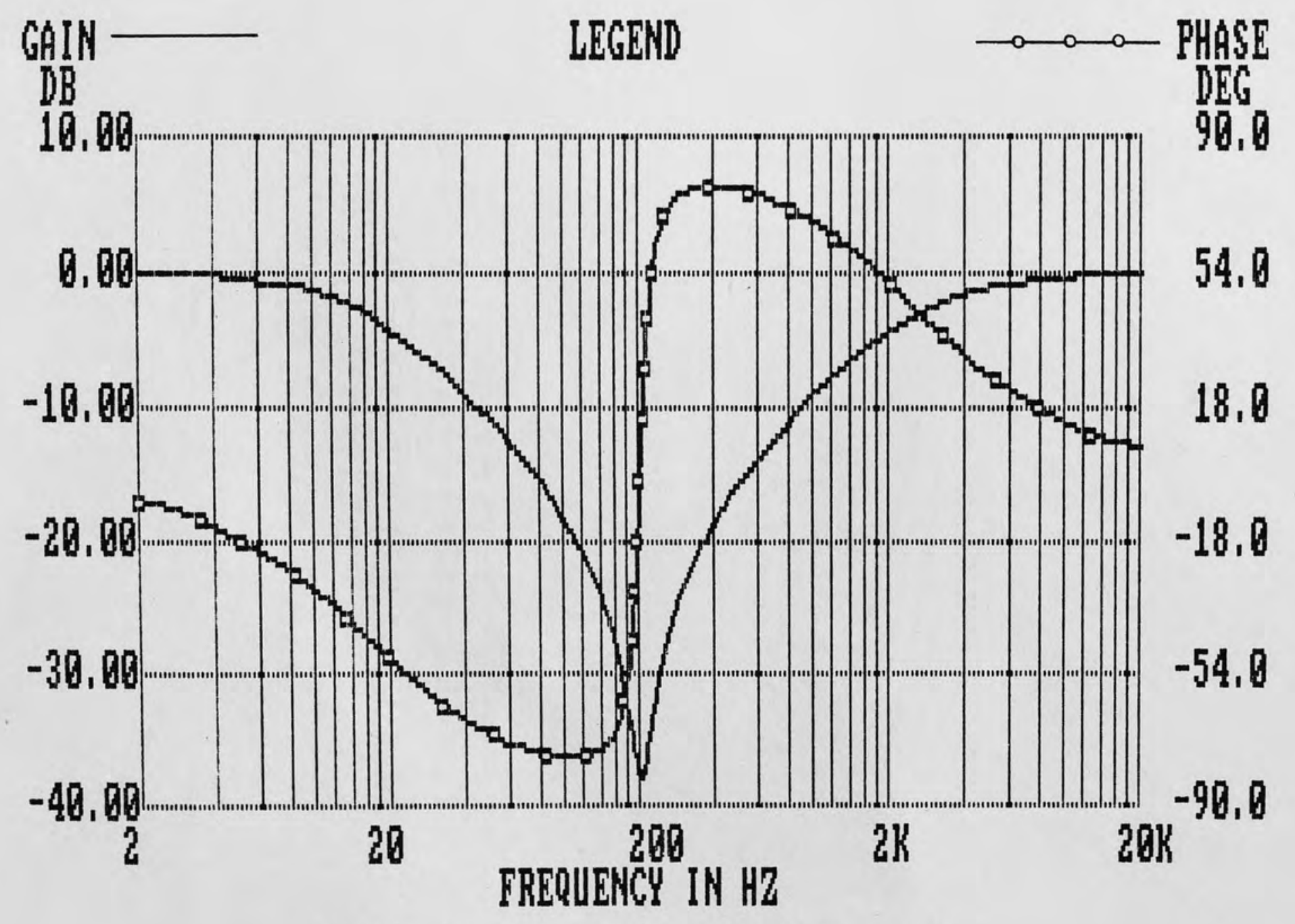

Figure 31. Lower Order Biquad Response. 


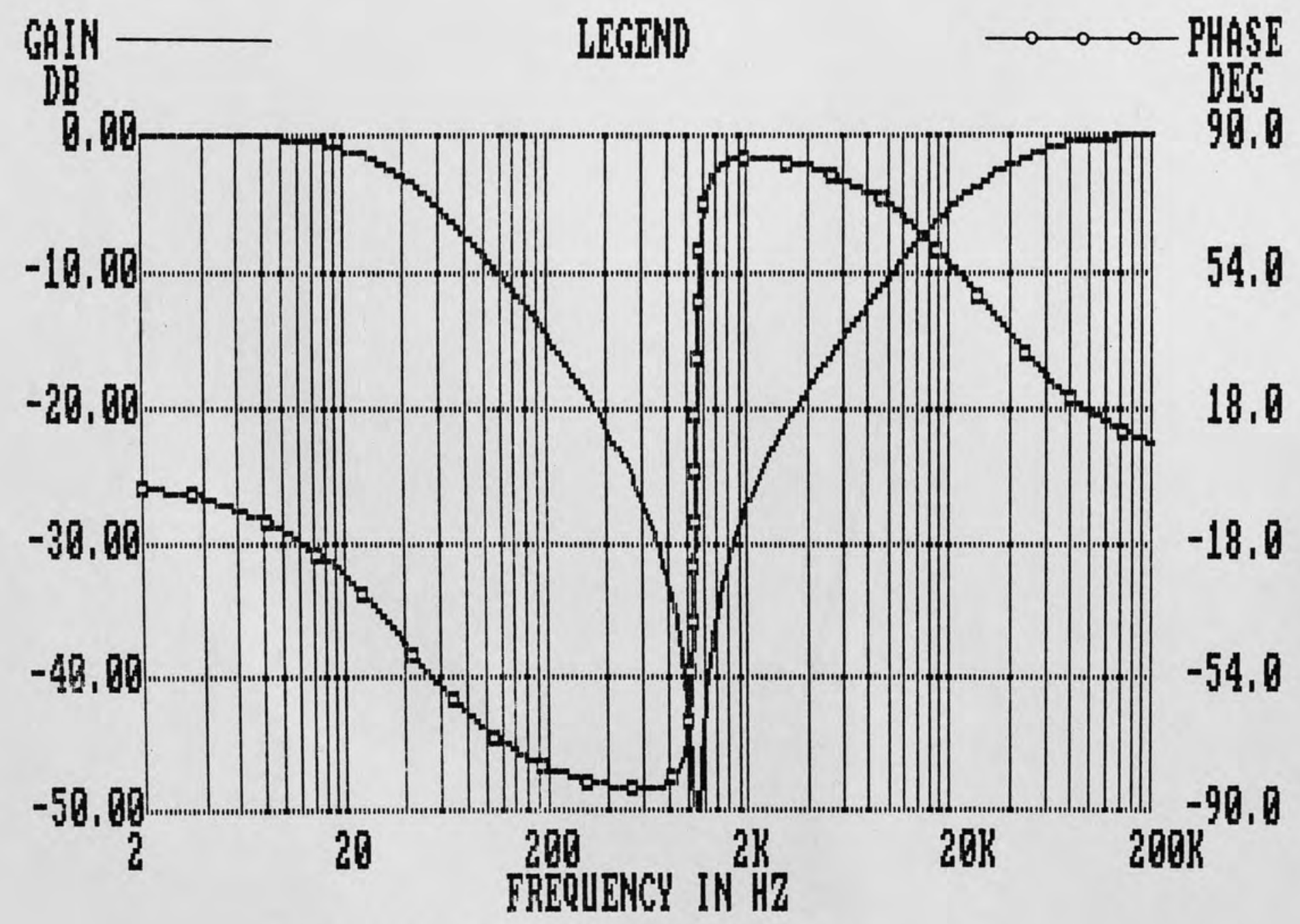

Figure 32. Higher Order Biquad Response. 


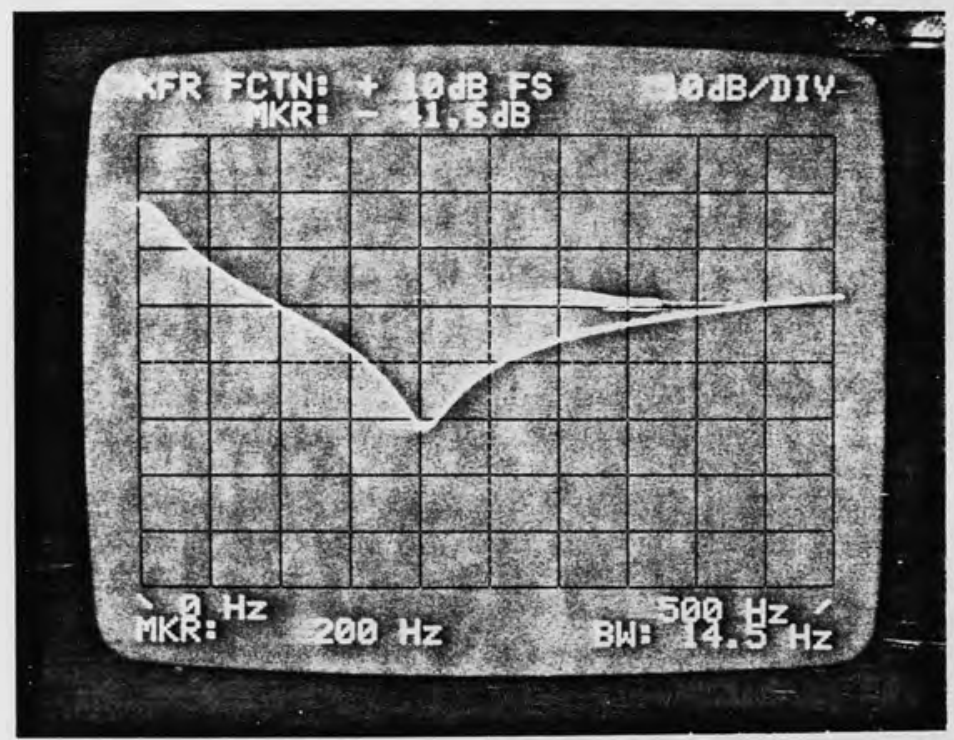

Figure 33. Lower Order Biquad Photographed Response.

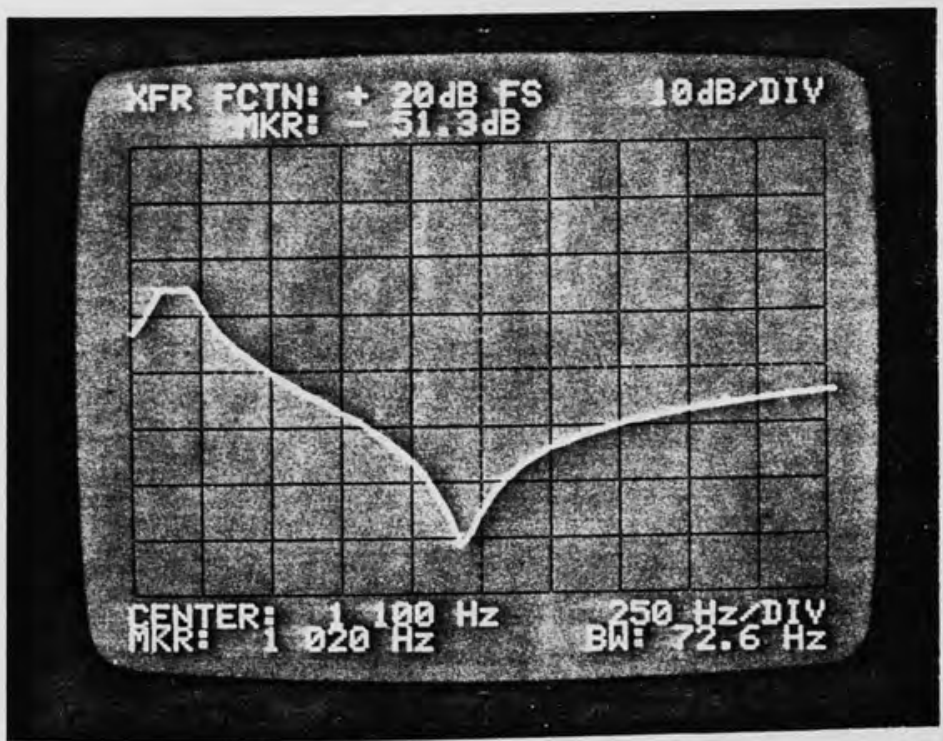

Figure 34. Higher Order Biquad Photographed Response. 


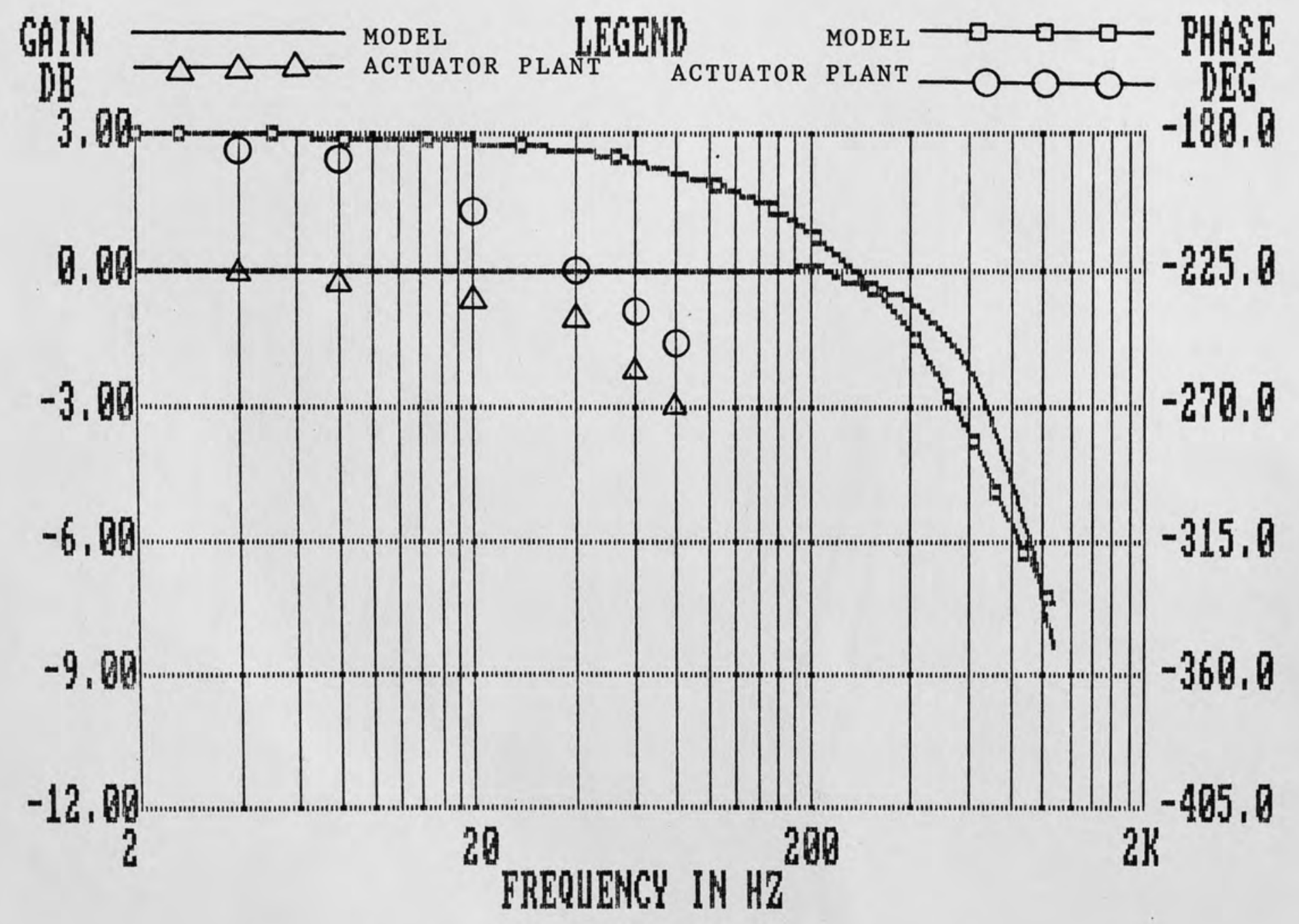

Figure 35. Actual System Closed Loop Response. 


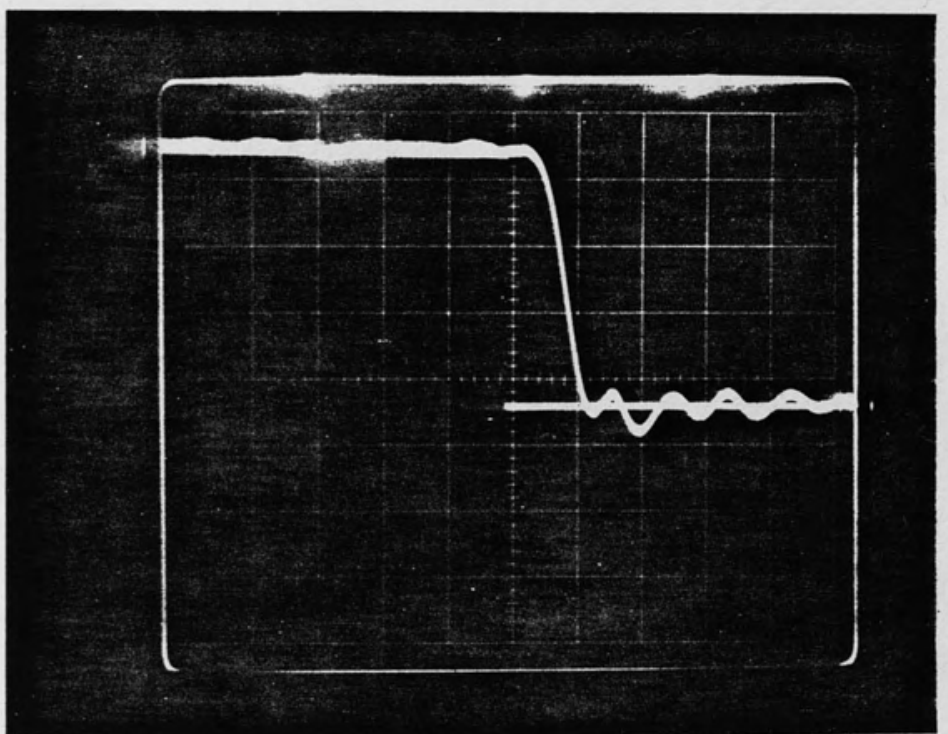

Figure 36. Photographed Step Response. 


\section{CONCLUSIONS AND EXTENSIONS}

This paper has presented a method for increasing the control loop used in a piezoelectric actuated scanning mirror system from a type $\emptyset$ to a type 1. This was achieved by placing the piezoelectric actuator in the feedback path of an operational amplifier, which introduced a free integrator into the forward path of the control loop.

A model which simulated the actuator response was developed and its parameters determined. This model was used in the subsequent analysis to find open and closed loop frequency responses of the actuator mechanism, for both uncompensated and compensated systems.

Compensation was designed to eliminate undesired pole locations and improve system response. This increased the bandwidth and stability of the closed loop system.

The position sensor was upgraded from that used in the Tomasetti prototype to reduce error from thermal drift and RF noise.

Finally, the physical system was compared to the model used in the analysis and with the Tomasetti prototype. The model compared favorably with the physical system and showed an improvement over the Tomasetti prototype with zero steady state error to a step input instead of nine percent. 
The actual bandwidth of the system was narrower than anticipated. In observing the loop response with the loop closed, a non-linearity was present that did not appear in the open loop response. The open loop response followed the response shown in Figure 23 very closely. However, when the loop was closed and the reference frequency increased, the loop response showed a non-linearity at a frequency which appeared to be amplitude and bias level dependent. This non-linearity introduced a very sharp phase shift about the frequency at which it appeared. This has the effect of robbing bandwidth, as the phase margin is reduced when additional phase shift is introduced. This is the reason for the difference between the predicted and actual gain margin. As much gain as possible was inserted to increase the bandwidth of the system, thus reducing the gain margin.

The non-linearity is not readily compensated for. It is suspected that the material bonding the mirror to the piezoelectric (which probably has compliance as well as damping properties) introduces this phenomenon. Further research on this phenomenon could be conducted in order to reduce the effect it has on the bandwidth.

Research on improving the angular deflection (limited to the opamp output voltage swing) could be carried out utilizing the inherent type 1 control loop with the actuator in the feedback path. Practical limitations in 
supply, voltage rails limit actuator deflection range. Limitations in opamp output current limits bandwidth. This is due to the capacitive loading of the actuator causing a slew rate limiting effect.

Possible use of two opamps, each driving one of the monomorph piezoelectric materials on the bimorph in its feedback path, would effectively double the voltage swing on the actuator. This would increase the deflection range capabilities greatly. Possible paralleling of two opamps for increased output current would alleviate slew rate limitations due to the capacitive loading of the actuators. This would probably be a difficult procedure at best.

This paper did show that the electrically capacitive property of the piezoelectric actuator allowed a free integrator to be introduced into the forward path of the control loop. The resulting zero steady state error was demonstrated for a step input. 
[1] Tomasetti, Thomas J.

Optimizing Scanning Mirror System Performance Using Solid State Piezoelectric Actuators. Master's Thesis. Orlando, Florida, University of Central Florida, 1986, pp. 3-9, 13-16.

[2] D'Azzo, Houpis. Linear Control System Analysis and Design. New York: MaGraw-Hill Book Company, 1981, pp. 192-197, 2ø4-2ø5, 361-363.

[3] MICROCAP II Electronic Circuit Analysis Program. Sunnyvale, California: Spectrum Software, 1986.

[4] Savant, Roden, Carpenter. Electronic Circuit Design. Menlo Park, California: The Benjamin/Cummings Publishing Company, Inc, 1987, pp. 31-33.

[5] Martin, Robert.J. Analysis and Synthesis of Active Feedback Applied to Piezoelectric Devices. Doctoral Dissertation. Orlando, Florida, University of Central Florida, 1984, pp. 6-8.

[6] PROGRAM CC Controls Analysis Program. Hawthorne, California: Systems Technology Inc, 1985.

[7] Pavlinko, Jerrold. Extending the Power Bandwidth of a Piezoelectric Bender Actuator. Master's Thesis. Orlando, Florida, University of Central Florida, 1987, pp. 6Ø-64.

[8] "Piezoelectric Technology Data for Designers." Bedford, Ohio: Vernitron Piezoelectric Division, pp. 1-3, 12, 15-17. 